\title{
On Deriving CED Effects from the PIC
}

Gereon Müller, Universität Leipzig ${ }^{\ddagger}$

\begin{abstract}
This paper shows that a version of the Condition on Extraction Domain (CED; Huang (1982)) can be derived from the Phase Impenetrability Condition (PIC; Chomsky (2001; 2008) if the following assumptions are made: (i) All syntactic operations are driven by features of lexical items. (ii) These features are ordered on lexical items. (iii) All phrases are phases. (iv) Edge features that trigger intermediate movement steps can only be added before the phase head becomes inert. Given (i-iv), it follows from the PIC that extraction from XP is blocked if the operation that has merged XP is the final operation taking place in a phase: A last-merged specifier is a barrier because no edge feature can be inserted that might extract some item out of it; this induces a PIC violation on the following cycle. The analysis can be extended to cover freezing effects. Furthermore, it predicts the existence of a phenomenon that I call melting effect. I show that melting effects occur in German and Czech: Local scrambling in front of what would otherwise qualify as a last-merged specifier renders the specifier transparent for extraction.

The single most important assumption of the present proposal is that the timing of edge feature insertion is crucial ('before' vs. 'after' in (iv)). Accordingly, the analysis can be viewed as an argument in support of a strictly derivational organization of grammar.
\end{abstract}

\section{Keywords}

Condition on Extraction Domain, Phase Impenetrability Condition, Strict Cycle Condition, phase, edge feature, scrambling, freezing, melting, derivation

\footnotetext{
$\ddagger$ For comments, discussion, or data (judgements), I would like to thank two reviewers for Linguistic Inquiry, Klaus Abels, David Adger, Anke Assmann, Elena Anagnostopoulou, Petr Biskup, Hagit Borer, Pavel Caha, Eric Fuß, Hans-Martin Gärtner, Doreen Georgi, Günther Grewendorf, Patrick Grosz, Hubert Haider, Fabian Heck, Roni Katzir, Hans van de Koot, Ivona Kučerová, Winnie Lechner, Denisa Lenertová, David Pesetsky, Omer Preminger, Marc Richards, Arnim von Stechow, Wolfgang Sternefeld, Jochen Trommer, and audiences at GGS 32, Universität Stuttgart (May 2006); the syntax workshop of the 34th Österreichische Linguistik-Tagung, Universität Klagenfurt (December 2006); the MIT linguistics colloquium (March 2007); the 30th GLOW Colloquium, University of Tromsø (April 2007); Universität Frankfurt (July 2007); and Universität Leipzig (July 2007).
} 


\section{Introduction}

The goal of this paper is to answer the question of how the effects of the Condition on Extraction Domain (CED; Huang (1982), Chomsky (1986; 1995; 2008), Cinque (1990), Manzini (1992)) can be made to follow under minimalist assumptions, according to which concepts like government, L-marking, and barrier are not available and specific constraints on movement (like the CED) are to be abandoned if possible. A simple version of the CED that is based on the notion of barrier is given in (1). ${ }^{1}$

\section{(1) Condition on Extraction Domain (CED):}

a. Movement must not cross a barrier.

b. An XP is a barrier iff it is not a complement.

I will argue that CED effects follow from the Phase Impenetrability Condition (PIC; see Chomsky $(2000 ; 2001 ; 2008))$ that is first and foremost motivated as a constraint that reduces computational complexity by minimizing search space in derivations. The version of the PIC that I adopt here is one of the two versions envisaged in Chomsky (2001) (the stricter one, at least at first sight; see Richards (2004; 2007) for extensive discussion).

(2) Phase Impenetrability Condition (PIC):

The domain of a head X of a phase XP is not accessible to operations outside XP; only X and its edge are accessible to such operations.

\footnotetext{
1 There are other attempts to derive (some version of) the CED, by invoking, for instance, specific assumptions about cyclic spell-out (see Uriagereka (1999), Nunes \& Uriagereka (2000), Nunes (2004) for one type of appraoch, and Johnson (2003) for another), or by relying on specific assumptions about the nature of elementary operations like Move and Agree (see particularly Sabel (2002) and Rackowski \& Richards (2005)). Alternatively, CED effects have been approached in terms of a general theory of freezing (see Kitahara (1994), Takahashi (1994), Boeckx (2003), Gallego \& Uriagereka (2006), Stepanov (2007); and Rizzi (2006; 2007) for a somewhat narrower concept of freezing that does not derive CED effects). I cannot discuss these alternative approaches in any detail here, let alone do them justice; see Müller (2009, ch. 2) for a critical overview. Suffice it to note that the first kind of approach is incompatible with the assumption that only the complement of a phase head is affected by spell-out whereas the specifier domain and the head itself remain available for further operations on subsequent cycles (Uriagereka/Nunes), or with the assumption that there is a phrase-structural difference between specifiers and adjuncts (Johnson); that the second type of approach seems to invariably rely on special assumptions that mimic assumptions in Chomsky's (1986) theory of barriers (e.g., Rackowski \& Richards (2005) postulate that an argument needs to undergo Agree with v in order to become transparent for extraction, which distinguishes specifiers of v from complements of V but looks similar to the notion of L-marking in Chomsky (1986); in Sabel's (2002) approach, extraction from subjects and adjuncts is argued to be impossible because these items are not
} 
For present purposes, we can assume that an item is in the edge domain of a head X iff it is a (possibly non-unique) specifier of $\mathrm{X}$, where a specifier is a non-first merged (i.e., noncomplement), non-head item. The PIC forces successive-cyclic movement via phase edges. Accordingly, it must be ensured that the intermediate movement steps that are required by the PIC are indeed permitted. Given a general Last Resort principle according to which all syntactic operations are feature-driven (see below), movement to intermediate phase edges must be triggered by appropriate features. ${ }^{2}$ These edge features cannot be obligatorily present on phase heads because they lead to a crash if the number of items that need to be attracted to a phase edge in the course of successive-cyclic movement does not equal the number of movementtriggering features on the phase head. To ensure that edge features for intermediate movement steps are only present on a phase head if they are needed, a condition like (3) can be assumed (see Chomsky (2000, 109), Chomsky $(2001,34)$, and Chomsky $(2008,149))$. I refer to this condition as the Edge Feature Condition here and in what follows.

\section{(3) Edge Feature Condition (EFC):}

The head X of phase XP may be assigned an edge feature after the phase XP is otherwise complete, but only if that has an effect on outcome.

Given (3), phase heads can be assigned additional (i.e., non-inherent) edge features in the course of the derivation "if that has an effect on outcoume", i.e., if that serves to implement intermediate movement steps required by the PIC. ${ }^{3}$ Of course, an important question is what it means for edge feature insertion to have "an effect on outcome". However, I will not focus on this issue in what follows since it is orthogonal to the main plot of this paper - for present purposes, it may suffice to assume that there is a sufficiently local way to determine whether features

merged with a lexical head, and the required S-projection cannot be formed); and that the third type of approach is incompatible with the existence of CED effects where an XP is a barrier in its in situ position. Perhaps most importantly, all these approaches have nothing to say about melting effects, a class of data that I will introduce in section 5 below, and that I will argue to corroborate the analysis to be developed in what follows.

2 Throughout this paper, I assume that intermediate movement steps involve genuine movement operations rather than acyclic locality-driven trace insertion, as proposed in Chomsky (1993), Takahashi (1994), and Boeckx (2003). If movement to intermediate positions exists, it may be either feature-driven or forced in some other way, in minimal violation of Last Resort; see McCloskey (2002) vs. Heck \& Müller (2003) for the two options. I adopt the former approach in what follows.

${ }^{3}$ Such an introduction of edge features in the derivation will presumably have to be construed as violating the Inclusiveness Condition (see Chomsky (1995; 2000; 2001; 2008)). Thus, this reasoning would seem to imply that whereas the prohibition against non-feature driven movement is strict, the prohibition against feature insertion is not; in other words, the Inclusiveness Condition is minimally violable whereas Last Resort is not. 
for successive-cyclic movement are needed or not, without actual look-ahead being required. ${ }^{4}$ From now on, I will simply tacitly presuppose that a requirement like "having an effect on outcome" is to be understood as part of the EFC.

The crucial assumption that I would like to put forward in this paper is that a minimal change in (3) effectively derives a version of the CED (in interaction with certain other, independently justified assumptions). In a nutshell, I suggest to replace after with before in (3). More specifically, the claim is that CED effects can be derived from the PIC if the following four assumptions are made: First, all syntactic operations are driven by features of lexical items. Second, these features are ordered on lexical items. Third, all phrases are phases. And, most importantly, fourth, edge features that trigger intermediate movement steps can be added only as long as the phase head is still active. The version of the CED that can be derived under these assumptions differs from the one given in (1) in a subtle but interesting respect: It is not simply non-complement XPs that are barriers; rather, those XPs are barriers that come into being as a result of the very last operation taking place within the phase. See (4).

(4) Condition on Extraction Domain (new version; to be derived from the PIC):

a. Movement must not cross a barrier.

b. $\alpha$ is a barrier if the operation that has merged $\alpha$ in a phase $\Gamma$ is the final operation in $\Gamma$.

In the following section, I introduce the four assumptions that are needed to derive (4). ${ }^{5}$

\footnotetext{
${ }^{4}$ Some strengthened version of Chomsky's (2001) Activity Condition might achieve this. Alternatively, the approach in terms of a constraint Phase Balance developed in Heck \& Müller (2000; 2003), Fischer (2004), and Müller (2004) correctly predicts under which circumstances intermediate movement steps are legitimate. Adapting this latter approach (which originally envisages non-feature driven movement) to the present set of assumptions, we might say that edge feature insertion has an effect on outcome (in the sense presupposed in (3)) iff this is the only way to balance a phase; a phase counts as balanced if, for every movement-inducing feature on items in the numeration, there is an available matching feature. Finally, a feature is available (in this technical sense) if it is part of the edge domain of either the present root of the derivation, or part of the workspace of the derivation (i.e., the numeration and trees that have been created earlier). This ensures that exactly one edge feature will be added to an intermediate phase head in English questions like What did Mary give to whom?, attracting only one of the two VP-internal wh-phrases to an intermedate phase edge.

5 The four assumptions are not equally important. In fact, it turns out that only the last assumption, concerning the timing of edge feature insertion on phase heads, is really indispensable. The first three assumptions could in principle be replaced by alternative (for instance, weaker) statements, which would still yield some version of (4). I will address this issue in the conclusion. For the time being, I treat the four assumptions as equally important on the one hand, because they help to derive what seems to me to be the empirically most adequate version of the
} 


\section{Assumptions}

\subsection{All syntactic operations are feature-driven}

It is often assumed that the operations Agree and internal Merge (i.e., movement) are featuredriven. In addition, I presuppose that external Merge (i.e., Merge applying to items from the numeration, or from the workspace of the derivation) also does not come for free but must be triggered by appropriate features, viz., subcategorization features (see Svenonius (1994), Collins (2003), Adger (2003), Lechner (2004), Kobele (2006), Sternefeld (2006), and Pesetsky \& Torrego (2006), among others). Thus, on this view, all basic syntactic operations are feature-driven. ${ }^{6}$ More specifically, following Heck \& Müller (2007), I will assume that there are two types of features that drive operations: structure-building features (edge features and subcategorization features) trigger (internal and external) Merge operations; and probe features trigger Agree operations. Here and in what follows, structure-building features (for both basic Merge and movement) are accompanied by bullets $\left(\left[\bullet \mathrm{F}_{\bullet}\right]\right)$, and probe features are embraced by asterisks $([* \mathrm{~F} *]){ }^{7}$ In addition, there is a Last Resort condition which requires all syntactic operations to be driven by (structure-building or probe) features; see (5).

\section{(5) Last Resort (LR):}

Every syntactic operation must discharge either $[\bullet \mathrm{F} \bullet]$ or $[* \mathrm{~F} *]$.

\subsection{Features on lexical items are ordered}

Consider the question of how linking can be brought about in current derivational syntactic theories, i.e., how the order of $\Theta$-roles in argument structures of predicates in the lexicon is mirrored by argument realization in syntax. ${ }^{8}$ For examples like (6), the task is to derive that

CED; and on the other hand because they ensure that the overall reasoning is maximally perspicuous and explicit.

${ }^{6}$ See Chomsky $(2001 ; 2008)$ for a different view with respect to external Merge; and Chomsky $(2007 ; 2008)$ on an extension of this position to internal Merge.

7 This represents a combination of notational conventions that can be found in Roberts \& Roussou (2002), Adger (2003), Sternefeld (2006), and Heck \& Müller (2007). Note also that I presuppose that just like subcategorization features, edge features that trigger movement do not have to be neutral with respect to the properties of the items

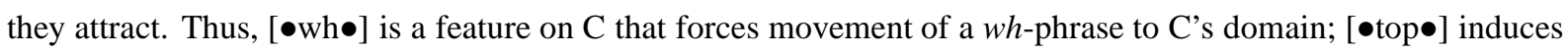
topic movement; and so forth. On the other hand, for the time being it can be assumed that edge features for intermediate movement are blind to the properties of the attracted item $([\bullet \mathrm{X} \bullet])$; but see section 4 below.

${ }^{8} \mathrm{I}$ am assuming here a standard approach to argument structure that relies on ordered lexical entries which predict a hierarchy of $\Theta$-roles (see, e.g., Bierwisch (1988), Wunderlich (1997), and Heim \& Kratzer (1998)). Things would be different under radical approaches like the one developed in Borer (2004), where argument structures are not basic, but are read off syntactic representations. 
$J o h n_{1}$ is interpreted as AGENT, $a$ book $_{2}$ as THEME, and Mary 3 as GOAL.

(6) $\mathrm{John}_{1}$ gave a book 2 to Mary 3

I will adopt an approach to linking in minimalist grammars that has its roots in categorial grammar, and a long tradition in transformational and phrase structure grammar (see Lewis (1972), Pollard \& Sag (1994), Wunderlich (1997), Lechner (2004), and Kobele (2006; 2009), among many others). According to this approach, $\Theta$-roles are ordered in lexical entries of predicates, and they are mapped onto a list of categorial subcategorization features (i.e., structure-building features: $[\bullet \mathrm{F} \bullet]$ ) in reverse order, as schematically depicted in (7). There must then be a condition ensuring that subcategorization features are discharged one after the other, beginning at the top of the hierarchy (see below for a specific suggestion).

(7) a. $\Theta$-roles:

$$
\Theta_{1} \gg \Theta_{2} \gg \Theta_{3}
$$

$($ AGENT $\gg$ THEME $\gg$ GOAL)

b. Subcategorization features:

$$
[\bullet \mathrm{P} \bullet]_{3} \succ[\bullet \mathrm{D} \bullet]_{2} \succ[\bullet \mathrm{D} \bullet]_{1}
$$

Furthermore, I assume that there can also be subcategorization features that do not go back to $\Theta$-grids. These kinds of subcategorization features play a role in structure-building operations involving functional categories, and they also enter argument lists of lexical items. For example, VP is not $\Theta$-marked by $\mathrm{v}$, but $\mathrm{v}$ has a subcategorization feature $[\bullet \mathrm{V} \bullet]$ that permits Merge of $\mathrm{v}$ and VP; and similar reasonings apply in the case of Merge (T,vP) and Merge (C,TP) (also see Adger (2003) for discussion of this issue, with a different conclusion). At this point, the question arises of how an external argument DP comes to be base-generated as the specifier of v. Based on Larson (1988) and subsequent work, two options have been pursued. One possibility (adopted in approaches that correlate $\mathrm{v}$ with causation or some related semantic concept; see Hale \& Keyser (2002), Harley (1995), Kratzer (1996), Adger (2003), Ramchand (2003), Schäfer (2007), and references cited in these works) is that AGENT DPs are introduced by v. In the present approach, this would amount to a feature list $[\bullet \mathrm{V} \bullet] \succ[\bullet \mathrm{D} \bullet]$ on $\mathrm{v}$, with $[\bullet \mathrm{V} \bullet]$ discharged by Merge $(\mathrm{v}, \mathrm{VP})$ before $[\bullet \mathrm{D} \bullet]$ is discharged by Merge $\left(\mathrm{v}^{\prime}, \mathrm{DP}\right)$. On this view, transitive verbs take only one argument; and ditransitive verbs subcategorize for two arguments (rather than three arguments, as in (7-b)). Alternatively, $v$ is motivated solely by considerations pertaining to phrase structure geometry; external arguments remain true arguments of $\mathrm{V}$, even though they are merged in the specifier of $v$ (see Haider $(2000 ; 2006)$ for an analysis along these lines, and Georgi \& Müller (2008) for an implementation of this idea in terms of head movement by reprojection). Here I adopt the former view: AGENT DPs are arguments of $\mathrm{v}$. Thus, (agentive) $\mathrm{v}$ is equipped with an ordered set of structure-building features $[\bullet \mathrm{V} \bullet] \succ[\bullet \mathrm{D} \bullet]$ 
- first, the VP argument of $\mathrm{v}$ is merged (discharging $[\bullet \mathrm{V} \bullet]$ ), and then its DP specifier enters the structure (discharging $[\bullet \mathrm{D} \bullet]$ ). Of course, Last Resort must be revised appropriately so as to be sensitive to the order of structure-building features; this is done in (8).

(8) Last Resort (LR, revised):

a. Every syntactic operation must discharge either $[\bullet \mathrm{F} \bullet]$ or $[* \mathrm{~F} *]$.

b. Only features on the top of a feature list are accessible.

(8-b) presupposes that a discharged feature is removed from the lexical item, and deleted. Issues related to morphological realization of case and agreement features may ultimately demand a slightly more complicated approach (according to which discharged features become inactive for further processes in the sense of (8-b) but remain accessible for morphological realization; see Adger (2003), Müller (2008) for discussion); but for present purposes we may keep to the simplest assumption.

The question arises of whether probe features on a lexical item are treated in the same way as structure-building features. In line with the definition in (8), I assume that this is indeed the case, for reasons of symmetry alone: Probe features show up on a separate stack (though their order will not play a role in this paper). Under these assumptions, there are two stacks of features on lexical items - one for structure-building features, and one for probe features. Consequently, given Last Resort in (8), lexical heads look like push-down automata: They are characterized by a last-in/first-out property (although so far, I have exclusively been concerned with the first-out part; the last-in part will be highlighted below).

\subsection{All phrases are phases}

The third assumption concerns the notion of a phase itself. Standardly, it is assumed that $\mathrm{vP}$ and CP are phases (see Chomsky (2000; 2001; 2008)), plus perhaps DP (see Svenonius (2004), Heck \& Zimmermann (2004), Matushansky (2005), Kramer (2007), Heck et al. (2007)), and possibly TP as a (parametrized) alternative (see Richards (2004; 2007)). In contrast, it has also been argued that all XPs qualify as locality domains for movement (see Koster (1978), Riemsdijk (1978)). Successive-cyclic movement via all intermediate XP edges has been assumed, inter alia, in Sportiche (1989), Takahashi (1994), Agbayani (1998); Chomsky (1995; 2005; 2008), Bošković (2002), Boeckx (2003), Müller (2004), and Boeckx \& Grohmann (2007). ${ }^{9}$ Given the present set of assumptions as background, it seems to me that the simplest way to bring about highly local successive-cyclic movement via phrase edges is to assume that all phrases

\footnotetext{
${ }^{9}$ Also compare the concept of SLASH feature percolation in Gazdar (1981); Gazdar et al. (1985), and the related concepts of "gap phrase" and "operator feature percolation" in Koster (2000) and Neeleman \& van de Koot (2007).
} 
are phases; and this is what I will do in what follows. Thus, if every XP is a phase, the PIC forces intermediate movement steps to all phrase edges. ${ }^{10}$

Needless to say, such an approach makes it necessary to reconsider a substantial part of the evidence that has been brought forward in support of a less general, category-selective concept of phases. I cannot possibly provide comprehensive discussions of all the relevant issues here; I will confine myself to a few remarks concerning the core cases (see Müller (2009) for extensive treatment of these issues).

First, phases have been correlated with cyclic spell-out domains. However, the first thing to note is that the correlation is not perfect in the first place (it is the complement domain of the phase head that is spelled out, rather than the phase as such - edge and head material must be available for operations on the next phase level). Moreover, domains for cyclic spell-out have also been argued to be potentially smaller than the classical phase (cf. Uriagereka (1999)), perhaps radically so (see Epstein \& Seely (2002)).

Second, closer inspection of the literature on morphological and other reflexes of successive cyclicity reveals that that they are not always confined to the $\mathrm{CP}$ or vP domains (as is the case with, e.g., complementizer selection in Modern Irish discussed in McCloskey (1979; 2002), or possibly the instances of $w h$-agreement in Chamorro discussed in Chung (1994)). For instance, focus movement in Ewe looks like a clear counter-example (at least at first sight) because the morphological reflex shows up in the TP domain (see Collins (1993; 1994)). Similarly, tonal downstep in Kikuyu is a reflex of successive-cyclic movement that does not exclusively identify CP or vP edges (cf. Clements et al. (1983)). See Lahne (2009) for more general discussion.

Third, as far as I can tell, assuming all intervening phrase edges to be landing sites for intermediate movement steps is fully compatible with evidence from reconstruction (see Fox (2000), Nissenbaum (2000)).

Fourth, Abels (2003) advances an argument for designated intermediate landing sites that is based on reflexivization options in English, and that excludes the TP domain from the set of intermediate landing sites; but the validity of the argument is called into question in Boeckx \& Grohmann (2007), Boeckx (2008), and Abels \& Bentzen (2008).

Assuming that other arguments for designated phase categories can be refuted in the same way, I would like to contend that there is every reason (not least of all because phases are motivated on the basis of complexity considerations) to assume that all phrases are phases. Consequently, wh-movement must proceed via every XP edge domain on its way to its ultimate

\footnotetext{
${ }^{10}$ An alternative type of approach that I will not pursue here envisages phases as more flexible objects; see Grohmann (2000), Marušič (2005) Gallego \& Uriagereka (2006), den Dikken (2007), and Gallego (2007).
} 
target position (the $\mathrm{C}_{[\bullet w h \bullet]}$ node that attracts it), given the PIC.

\subsection{Edge feature insertion}

Finally, as noted, the most important assumption that is needed to derive the CED in (4) from the PIC concerns the insertion of edge features. According to the Edge Feature Condition in (3), an edge feature may be inserted on a phase head so as to trigger an intermediate movement step (and thereby avoid a PIC violation) only after the phase is otherwise complete. Chomsky $(2000,109)$ defines the stage of the derivation at which a phase is "complete" in this sense as follows: A phase is complete if it has "exhaust[ed] the lexical subarray from which it is derived". Assuming that all syntactic operations are triggered by the phase head, this would seem to strongly suggest that the phase head is inert once the phase is complete. Hence, the null hypothesis surely is that the phase is inaccessible for further internal modification at this point. From this perspective, subsequent edge feature insertion (as in (3)) is a peculiar operation. I would therefore like to propose that after is to replaced with before in the definition of the Edge Feature Condition in (3): Edge features can only be inserted as long as the phase head is active. Given the assumption that all syntactic operations are (induced by properties of a phase head and) feature-driven (see subsection 2.1 above), activity of a phase head (in the relevant sense) can be defined as follows: A phase head is active as long as it has (structure-building or probe) features to discharge; otherwise it counts as inactive. ${ }^{11}$ This leads to the revised version of the Edge Feature Condition in (9).

(9) Edge Feature Condition (EFC, new version):

An edge feature $[\bullet \mathrm{X} \bullet$ ] can be assigned to the head $\gamma$ of a phase only if (a) and (b) hold:

a. $\quad \gamma$ has not yet discharged all its structure-building or probe features.

b. $[\bullet X \bullet]$ ends up on top of $\gamma$ 's list of structure-building features.

(9-a) incorporates the new assumption about the timing of edge feature insertion; (9-b) just makes precise the assumption that phase heads act like pushdown automata - an edge feature that is assigned to a phase head ends up on top of the stack of structure-building features that is present on the phase head (this then fully accounts for the last-in/first-out property mentioned at

\footnotetext{
11 Thus, access to a concept like "lexical subarray" is not required in the present approach to determine inertness of a phase head. As a matter of fact, the Phase Balance approach mentioned in footnote 4 depends on the assumption that the whole numeration is accessible at all points of the derivation; and the same goes for the approach to freezing developed in section 4 below. In principle, it would still be possible to postulate designated subarrays of the numeration that correspond to phases; I will leave open the question of whether such a move is warranted.
} 
the end of subsection 2.2). ${ }^{12}$ To sum up, the important consequence of (9) (in interaction with

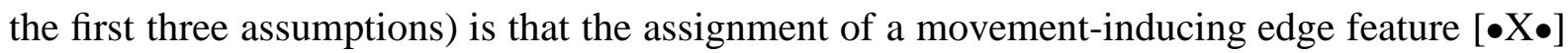
to a phase head $\gamma$ can take place only to the top of a feature list on $\gamma$, and that $\gamma$ must have a non-empty feature list at this point.

From these four assumptions, the CED in (4) follows as a theorem. This is shown in the following section.

\section{Deriving the Condition on Extraction Domain}

\subsection{Merge}

Let us ignore probe features on phase heads for the moment, and focus on structure-building features only. Given this proviso, the CED in (4) can be derived as follows. First, if an edge feature feature $[\bullet \mathrm{X} \bullet]$ is to be inserted on a phase head $\gamma, \gamma$ must contain at least one other feature at this point; otherwise it is inert and cannot be affected by edge feature insertion (this follows from clause (a) of the EFC in (9)). Second, edge feature insertion must go to the top of $\gamma$ 's list of structure-building features (this follows from clause (b) of the EFC in (9)). Third, if an edge feature $[\bullet \mathrm{X} \bullet]$ has been inserted on a phase head's stack of structure-building features, it is discharged again immediately, as an instance of the last-in/first-out property of phase heads (this follows from clause (b) of LR in (8)). Fourth, and most importantly, this means that it is impossible to insert an edge feature for a category $\alpha$ that is merged in $\Gamma$ (i.e., the maximal projection of a phase head $\gamma$ ) as the last operation taking place in $\Gamma$ (because of the EFC in (9) - in this case, at the point where $\alpha$ is part of the structure, the head of $\Gamma$ has no feature left, and has therefore become inert, making edge feature insertion impossible). Fifth, this in turn implies that a moved item $\beta$ in the edge domain of a category $\alpha$ merged last in a phase $\Gamma$ is not accessible anymore outside $\Gamma$ : If $\alpha$ is last-merged, an edge feature cannot be placed on the head of $\Gamma$ anymore, and a category that is part of $\alpha$ cannot be moved out of $\alpha$, to an outer specifier of $\Gamma$. Therefore, once the derivation proceeds by combining $\Gamma$ with some new item from the numeration, the PIC in (2) renders $\beta$ in $\alpha$ inaccessible. ${ }^{13}$ Sixth, it thus follows that extraction from $\alpha$ is predicted to be impossible if $\alpha$ enters a phase as a result of the last operation taking place in that phase, as a consequence of the phase head's features (because of the PIC).

\footnotetext{
12 As observed by Winnie Lechner (p.c.), the fact that feature assignment must always go to the top of a feature stack is arguably just a consequence of a general principle regulating derivational structure generation, viz., the Strict Cycle Condition (SCC). The SCC will become relevant later.

${ }^{13}$ Note that this reasoning presupposes a non-recursive notion of edge, such that the edge $\beta$ of a category $\alpha$ is not part of the edge of a phase $\Gamma$ even if $\alpha$ is part of the edge of $\Gamma$.
} 
Therefore, and this concludes the argument, given that (outer) specifiers are last-merged in their projections, they are predicted to be barriers for movement: The CED in (4) is derived.

As an illustration, consider the (possibly simplified) model of clause structure in (10).

$$
(\ldots)\left[_{\mathrm{CP}} \alpha_{1} \mathrm{C}\left[\mathrm{TP} \alpha_{2} \mathrm{~T}\left[{ }_{\mathrm{vP}} \alpha_{3} \mathrm{~V}+\mathrm{v}\left[\mathrm{vP} \alpha_{4}\left[\mathrm{v}^{\prime} \mathrm{t}_{V} \beta\right]\right]\right]\right]\right]
$$

Assume that $\alpha_{n}$ in (10) is a specifier that is last-merged in its phase whereas $\beta$ is a complement. The task then is to derive (in accordance with (4)) that $\alpha_{n}$ is a barrier whereas $\beta$ is not (necessarily; see below) a barrier. Turning to (last-merged) specifiers first, it remains to be shown that no order of operations can yield a legitimate outcome if some item is to be extracted out of $\alpha_{n}$ in (10). Suppose first that edge feature insertion follows specifier feature discharge. This gives rise to the sequence in (11-a), which violates (9-a) - an edge feature is assigned to a phase head that has discharged all its inherent structure-building features and has thereby become inert. ${ }^{14}$ Suppose next that the order of operations is reversed, i.e., edge feature insertion precedes specifier feature discharge. There are two possible scenarios. One possibility is that the edge feature is assigned to the phase head, but does not end up on top of the phase head's stack of structurebuilding features; see (11-b). This violates (9-b) - inserted edge features must go to the top of a feature stack. Alternatively, edge feature insertion precedes specifier feature discharge, but this time, the edge feature is indeed assigned to the top of the stack, as in (11-c). Unfortunately, this does not help either, because of (8-b): After the edge feature is inserted, it has to go away directly, given Last Resort (attracting some category within the complement of the phase head to an outer specifier). Therefore, such an edge feature cannot serve to move anything out of $\alpha$ :

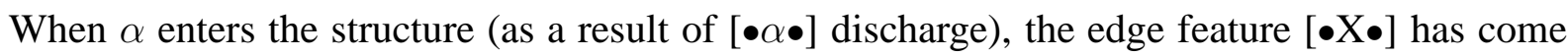
and gone already.

(11) Why specifiers in (10) are barriers:

a.

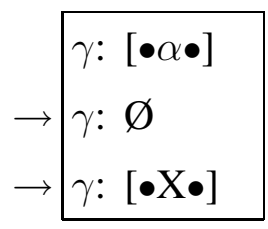

$\rightsquigarrow$ violates $(9-a)$

b.

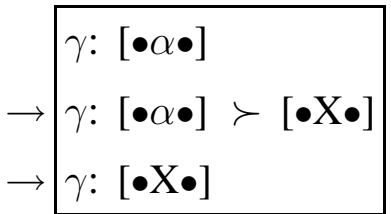

$\rightsquigarrow$ violates $(9-b)$

\footnotetext{
${ }^{14}$ A remark on notation: $\alpha$ refers to a syntactic category (a phrase, possibly with rich internal structure); in contrast, $[\bullet \alpha \bullet]$ is a subcategorization feature selecting the category label of $\alpha$. Thus, strictly speaking, "alpha" is ambiguous between a syntactic category and its label. This simplification is harmless.
} 


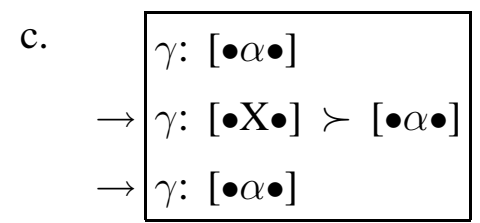

$\rightsquigarrow$ does not help because of $(8-b)$

To conclude, specifiers are barriers because of the PIC: There is no way to carry out an intermediate movement step from a last-merged specifier to the specifier of the minimal phase above it. At this point, the question arises of why complements are not barriers (or, more precisely, do not have to be barriers - see below). In (10), $\beta$, VP, vP, TP, and CP are complements that are firstmerged in their phases and have not yet discharged the final structure-building feature of the respective phase head's feature list; in other words, the operation that brings the complement into the structure is not the last structure-building operation carried out in the phase. Again, several a priori possible derivations need to be considered, but now, there has to be at least one derivation that succeeds. As it turns out, this derivation is straightforward. As shown in (12-a), no constraint is violated if edge feature insertion follows complement feature discharge but precedes specifier feature discharge. At the point where assignment of the edge feature to the phase head is called for (so as to move an item out of the complement $\beta$ to an outer specifier of the phase), the complement feature $[\bullet \beta \bullet]$ must have been discharged, but the specifier-creating feature $[\bullet \alpha \bullet]$ is still present on the head. Therefore, edge feature insertion finds a stage of the derivation where it can apply non-vacuously without violating the ban on modifying inactive phase heads incorporated into the EFC. Of course, alternative derivations that mirror those in (11-b) and (11-c) are excluded for the same reasons as before: If edge feature insertion applies very early and precedes complement feature discharge, either the inserted edge feature fails to end up on top of the phase head's feature stack (as in (12-b)), or the edge feature is discharged again immediately (by merging some arbitrary category), without being able to attract anything out of the complement (which is not yet part of the structure); see (12-c).

(12) Why complements in (10) do not have to be barriers:

a.

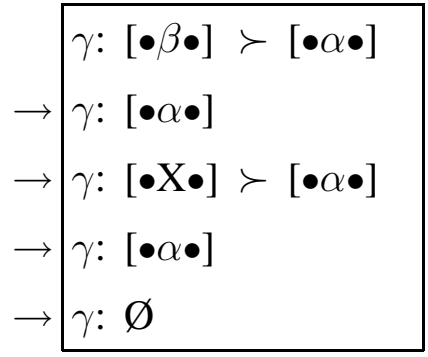

$\rightsquigarrow$ violates nothing

b.

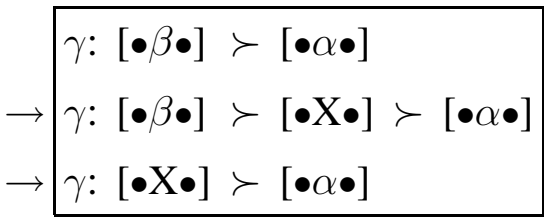

$\rightsquigarrow$ violates $(9-b)$ 
c.

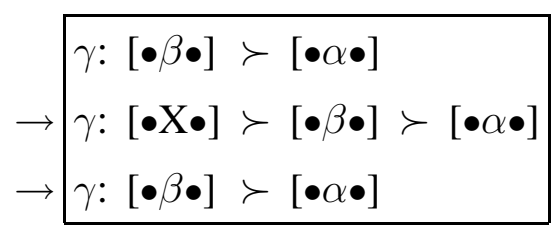

$\rightsquigarrow$ does not help because of (8-b)

Thus, movement out of complements can respect the PIC: There is a stage in the derivation where the complement feature has already been discharged (so that subsequent edge feature insertion can attract an item within the complement), but the specifier feature has not yet been discharged.

The present approach makes an interesting prediction concerning the exact nature of the landing site of intermediate movement steps: Intermediate movement steps to phase edges must take place before a (final) specifier is merged. Assuming that tucking in (in the sense of Richards (2001)) is not an option in natural languages (see below), this implies that subsequent Merge of a specifier ends up in a higher position. Thus, we end up with the result that an intermediate movement step (triggered by an edge feature that is not inherently present on a phase head) ends up in a specifier that is asymmetrically c-commanded (and preceded) by a category whose presence is due to an inherent (e.g., subcategorization) feature of the same phase head. I take this consequence to be somewhat unusual but entirely unproblematic. It is shown schematically in (13), where successive-cyclic movement of the complement of $\mathrm{V}$ (rather than out of the complement of $\mathrm{V}$ ) first takes place to an inner specifier of $\mathrm{V}$; then to an inner specifier of $\mathrm{v}$ (out of the complement VP); and then on to some specifier outside of the complement vP. ${ }^{15}$

$$
\underline{\mathrm{DP}_{2}} \cdots\left[\mathrm{vP}^{\mathrm{DP}} \mathrm{DP}_{1}\left[\mathrm{v}^{\prime} \underline{\mathrm{t}_{2}^{\prime \prime}}\left[\mathrm{v}^{\prime} \mathrm{V}+\mathrm{v}\left[\mathrm{vP}^{\mathrm{DP}} \mathrm{DP}_{3}\left[\mathrm{v}^{\prime} \underline{\mathrm{t}_{2}^{\prime}}\left[\mathrm{v}^{\prime} \mathrm{t}_{V} \underline{\mathrm{t}_{2}}\right]\right]\right]\right]\right]\right.
$$

This way, standard CED data are derived, like the Sentential Subject Constraint effect in English shown in (14) (assuming that the effect is indeed real, effective before clausal extraposition, and not an instance of something else, as argued by Koster (1978)); or the standard Subject Condition effect with DPs in (15). External argument CPs and DPs are merged in Specv as the last operation taking place in vP; an edge feature cannot be instantiated on v after the external argument has been merged (because the phase head is inert at this point); and subsequent movement of the wh-phrase in (14) and (15) out of the external argument therefore violates the PIC.

(14) a. $\left[\mathrm{DP}_{1}\right.$ Who ] did the reporters expect [CP that the principal would fire $\left.\mathrm{t}_{1}\right]$ ?

b. $*{ }_{\mathrm{DP}_{1}}$ Who $]$ was $\left[\mathrm{CP}\right.$ that the principal would fire $\left.\mathrm{t}_{1}\right]$ expected by the reporters ?

\footnotetext{
15 It can also be noted that the present approach is incompatible with Anti-Locality requirements on movement, as they have been advanced in Grohmann (2000; 2003) and Abels (2003): The first movement step to SpecV, e.g., is extremely local.
} 
c. $*{ }_{\mathrm{DP}_{1}}$ Who $]$ did $\left[\mathrm{CP}\right.$ that Mary was going out with $\left.\mathrm{t}_{1}\right]$ bother you ?

(15) a. $*\left[\mathrm{DP}_{2} \mathrm{Who}(\mathrm{m})\right]$ has $\left[\mathrm{DP}_{1}\right.$ a comment about $\left.\mathrm{t}_{2}\right]$ annoyed you ?

b. $*\left[\mathrm{PP}_{3}\right.$ About whom $]$ has $\left[\mathrm{DP}_{1}\right.$ a comment $\left.\mathrm{t}_{3}\right]$ annoyed you ?

The CED in its classical formulation covers subjects and adjuncts. The barrier status of adjuncts follows immediately if we assume that adjuncts are to be reanalyzed as last-merged specifiers of special functional projections (see Alexiadou (1997), Cinque (1999)). The reasoning is then identical to the one given before for subjects. Some standard English examples instantiating the Adjunct Condition part of the CED are given in (16). ${ }^{16}$

(16) a. $*{ }_{D_{D P}}$ Who $]$ did you get jealous [CP because I talked to $\left.t_{1}\right]$ ?

b. * ${ }_{\mathrm{PP}_{1}}$ To whom $]$ did they leave $\left[\mathrm{CP}\right.$ before speaking $\left.\mathrm{t}_{1}\right]$ ?

c. $*\left[\mathrm{DP}_{1}\right.$ Who $]$ did they leave $\left[\mathrm{CP}\right.$ before speaking to $\left.t_{1}\right]$ ?

Finally, given that dative ('affected') GoAL arguments are merged last in VP, in SpecV (in contrast to other GOAL arguments that are realized by PPs), they are predicted to invariably qualify as barriers, just like external arguments merged in Specv. This prediction seems correct for German; cf. (17-a) (external nominative DP as a barrier) and (17-b) (dative DP as a barrier); see Fanselow (1987; 2001a), Grewendorf (1989), and Müller (1995). ${ }^{17}$
a. *[PP ${ }_{1}$ Über wen $]$ hat $[\mathrm{DP}$ ein Buch
$\mathrm{t}_{1}$ ] den Fritz beeindruckt ? about whom has
a book $_{n o m}$ the Fritz acc $_{\text {impressed }}$

\footnotetext{
16 That said, it has sometimes been observed that adjuncts tend to be stricter islands than subjects, and less susceptible to cross-linguistic variation. The present analysis does not rule out the possibility that some other factor might additionally block extraction from adjuncts, or preclude what might exist as a way out for extraction from subjects in some languages after all (see section 6 for some speculations).

${ }^{17}$ Subject raising to SpecT is optional in German; so both a derivation in which the subject DP in (17-a) is in Specv, and one in which it is in SpecT, must be excluded. Also see Jurka (2008) for an experimental study showing that there are CED effects with in situ subjects in Specv in German.

It has sometimes been argued that certain kinds of subject DPs are transparent for extraction in German; see, e.g., Haider (1983; 1993) and Diesing (1992). As noted by Fanselow (2001a, 422), many of the putative counterexamples in German involve passive or unaccusative constructions with the nominative DP in situ, in a complement position, as in (i-ab). See the next subsection for an analysis, and also (22) below.
}

(i) a. $\quad\left[\mathrm{PP}_{1}\right.$ Über wen $]$ wurde $\left[\mathrm{DP}\right.$ ein Buch $\left.\mathrm{t}_{1}\right]$ gelesen ? about whom was a book $_{n o m}$ read

b. $\quad\left[\mathrm{PP}_{1}\right.$ Über wen ] ist [DP ein Buch $\mathrm{t}_{1}$ ] erschienen ? about whom is a book $_{n o m}$ appeared

The contrasts between extractions from nominative DPs with individual-level and stage-level predicates noted in 
b. $*\left[\mathrm{PP}_{1}\right.$ Über wen ] hat der Verleger [DP einem Buch $\left.\mathrm{t}_{1}\right]$ einen Preis gegeben ? about whom has the publisher $_{n o m}$ a book $_{d a t}$ a price $_{a c c}$ given

\subsection{Agree}

The present analysis makes two related predictions for extraction from objects that look problematic. First, given what has been said so far, we expect that THEME (accusative) objects can avoid becoming a barrier in VP only if there is something else that is merged later (e.g., a GOAL (dative) object). This prediction is not borne out; consider, e.g., the German examples in (18-a) (extraction from an accusative object in the presence of a higher dative object with a ditransitive verb) and (18-b) (extraction from an accusative object with a simple transitive verb). Second, as has been observed by Cattell (1976) and (from a slightly different point of view) Bach \& Horn (1976), movement out of THEME (accusative) objects is known to depend on a tight relation between $\mathrm{V}$ and $\mathrm{N}$ (the formation of a "natural predicate"); see the contrast between (18-b) and (18-c), which so far also remains without an explanation. Thus, the fact that accusative DPs in German (and other languages) that are simultaneously first- and last-merged in VP are partly, but not fully transparent local domains is not accounted for under present assumptions.

(18) a. [ ${ }_{\mathrm{PP}_{1}}$ Worüber ] hat er der Maria [DP ein Buch $t_{1}$ ] gegeben? about what has he nom the Maria $_{d a t}$ a book $_{a c c}$ given

b. [ $\mathrm{PP}_{1}$ Worüber ] hat der Fritz [DP ein Buch $\left.\mathrm{t}_{1}\right]$ gelesen ? about what has the Fritz nom $_{\text {a }}$ book ${ }_{a c c}$ read

c. $*\left[\mathrm{PP}_{1}\right.$ Worüber $]$ hat der Fritz $\quad\left[\mathrm{DP}\right.$ ein Buch $\left.\mathrm{t}_{1}\right]$ geklaut? about what has the Fritz ${ }_{\text {nom }}$ a book $_{a c c}$ stolen

Diesing (1992), to the extent that they are real, can presumably for the most part be reinterpreted along the same lines, as reflecting a difference between VP-internal complements and specifiers of v; see (ii-ab) (my judgements; Diesing assigns a $*$ to (ii-a)).

(ii) a. ??Was ${ }_{1}$ sind [DP $\mathrm{t}_{1}$ für Leguane ] intelligent ? what are for iguanas ${ }_{n o m}$ intelligent

b. Was ${ }_{1}$ sind [DP $\mathrm{t}_{1}$ für Leguane ] verfügbar? what are for iguanas ${ }_{n o m}$ available

(Here and in what follows, I presuppose that was für ('what for') phrases are DPs; however, the exact categorial status and internal organization of these arguments are not really important for any of the substantial points made in this paper. Still, it can be noted that the kind of structure attributed to was für phrases by Leu (2008) is incompatible with the present approach because it relies on the availability of extraction from a last-merged specifier.)

Other apparent counter-examples involve PPs headed by von ('of'), as in (iii-a). For these, a non-movement analysis seems systematically available; see the discussion around (29) in section 4. A similar reasoning applies in the case of DP split constructions such as (iii-b), which systematically violate constraints on extraction in German and may not involve movement at all in this language. 
There are various ways to account for the contrast in (18-bc). An approach that I assume to be essentially on the right track centers around the notion of "abstract incorporation" and can be traced back to Baker (1988); versions of this general approach have been developed in Müller (1995), Sauerland (1995), Davies \& Dubinsky (2003), and Schmellentin (2006), among others. The basic idea is as follows: Abstract incorporation of $\mathrm{N}$ into $\mathrm{V}$ (i.e., head movement of $\mathrm{N}$ to $\mathrm{V}$ at the level of Logical Form (LF)) must apply to remove an initial barrier status from an NP. ${ }^{18}$ Abstract incorporation may take place only at LF, but it can be viewed as coindexing under minimality (cf. the Head Movement Constraint, HMC) in syntax. ${ }^{19}$ Whether abstract incorporation can apply or not is partly determined by lexical factors: V-N:read-book is a natural predicate resulting from abstract incorporation, but V-N:steal-book is not (for most speakers); so abstract incorporation may take place in the former, but not in the latter case, removing the barrier in (18-b) but leaving it intact in (18-c).

This analysis arguably works well as such; however, there is a severe problem with the approach: The analysis is incompatible with DP-over-NP structures (see Abney (1987), Szabolcsi (1994); and Alexiadou et al. (2007) for a recent overview). The reason is that $\mathrm{N}$ cannot abstractly incorporate into $\mathrm{V}$ in the presence of an intervening $\mathrm{D}$; such a movement step would be expected to give rise to a HMC (or minimality) violation. I would therefore like to suggest a reanalysis of the abstract incorporation approach to extraction from nominal projections. Suppose that abstract incorporation does not involve movement at any stage of the derivation. Rather, it is an instance of Agree, in the following sense: If $\mathrm{V}$ and $\mathrm{N}$ form a natural predicate, they share an abstract feature $[* \mathrm{p} *] /[\mathrm{p}]$ (where ' $\mathrm{p}$ ' is mnemonic for 'natural predicate'). Agree requires c-command, but is less local: An intervening D is unproblematic. Given that abstract incorporation is reanalyzed as an instance of $[* \mathrm{p} *] /[\mathrm{p}]$ Agree, we can now assume that read-

(iii) a. ?[ $\left[\mathrm{PP}_{1} \mathrm{Zu}\right.$ diesem Problem ] haben [DP einige Briefe $\left.\left(\mathrm{t}_{1}\right)\right]$ den Sender erreicht to/concerning this problem have several letters ${ }_{n o m}$ the station reached

b. [NP Briefe ] haben mich [DP keine $\quad\left(\mathrm{t}_{1}\right)$ ] erreicht letters $_{n o m}$ have me none nom $_{\text {reached }}$

Finally, the most convincing counter-examples to the generalization that subject DPs in Specv (or, optionally, SpecT) are barriers for extraction in German typically involve configurations where the subject DP is adjacent to $\mathrm{V}$ as a result of object scrambling. I take this phenomenon to be real. As I will show in section 5, this is an instantiation of a systematic melting effect, and entirely expected under present assumptions.

18 Thus, head movement opens barriers. See Bobaljik \& Wurmbrand (2003), Gallego \& Uriagereka (2006), and den Dikken $(2007 ; 2008)$ for recent implementations of the idea that head movement extends local domains and thereby opens up barriers.

19 Alternatively, abstract incorporation may be viewed as overt, syntactic head movement that is accompanied by a pronounciation of the trace, as in Stechow (1992) and Fanselow (2001b). 
book involves a $[* \mathrm{p} *] /[\mathrm{p}]$ Agree relation (hence, a natural predicate), whereas steal-book does not; cf. (19).

(19) a. [ [vP $\left.\mathrm{V}_{[* p *]}\left[{ }_{D P} \mathrm{D}\left[\mathrm{NP}_{[p]} \mathrm{PP}\right]\right]\right]$

read book

b. [VP V [DP D [NP N PP ]]]

steal book

Of course, this analysis implies that Agree operations can find a way to avoid PIC violations that does not exist for movement (from non-edge domains of a phase). More specifically, it seems that either the PIC is relaxed for Agree operations (as has been proposed by Bošković (2007), among others), or that Agree can be successive-cyclic, proceeding from one head to the next one higher up (see Legate (2005)). A relaxation of Agree relations along these lines is required independently, and under standard (i.e., somewhat less local) conceptions of what a phase is (see Chomsky $(2000 ; 2001)$ ) for cases of long-distance agreement, at least for those cases of long-distance agreement that can be shown not to be parasitic on XP movement (as proposed by Polinsky \& Potsdam (2001) for Tsez), and that cannot be reanalyzed in terms of extremely local domains after all (see Boeckx (2004)). Given that cases of long-distance movement should not be taken to motivate a less restrictive concept of phase as such (as argued by Chomsky (2001) for Agree applying to $\mathrm{T}$ and a nominative object in Icelandic, and by Bhatt (2005) for longdistance agreement in Hindi), exempting Agree from the PIC and assuming cyclic Agree look like the most plausible options. ${ }^{20}$

Given that probe features on V can remove barrier status from an accusative object DP in VP, it must be ensured that this option does not arise for dative objects in SpecV - more generally, probe features on a phase head can never remove barrier status from a last-merged specifier (like an external argument in Specv). This follows if two assumptions are made. First, a probe

\footnotetext{
${ }^{20}$ Note that under the present set of assumptions, Agree operations must be permitted to cross a phase boundary even for instances of local case assignment - e.g., accusative case assignment by $\mathrm{v}$ to DP in VP. Note that this reasoning already suggests that it cannot be a case or agreement-related Agree relation between $\mathrm{v}$ and an object DP in VP that is responsible for the latter's mobility and transparency for extraction (notwithstanding the lexical variation visible in (18-b) vs. (18-c), which would remain unaccounted for): When an edge feature is needed to move an object DP (or something contained in that object DP) from (within) the complement position in VP to a SpecV position, $v$ is not yet present - so the pertinent probe feature must be located on V. Thus, a casebased approach might arguably work with instances of lexical case assignment by V, but it would not work with structural case assignment by v. - Curiously enough, lexical case-marking typically induces barrier status on the lexically case-marked DP, at least in a language like German. This does not yet follow in the present approach. In fact, additional assumptions would be necessary to ensure the mere possibility of a barrier status of lexically case-marked DPs. A stipulation that would yield the intended result would be that V can assign lexical case only after movement to v; note that this would be compatible with the SCC to be discussed below, in (20).
} 
feature cannot carry out Agree with (some item in) its specifier (see Chomsky $(2001 ; 2008)$ ). This follows from the assumption that Agree requires c-command, and is thus restricted to the complement domain of a head.

Second, a probe feature cannot carry out Agree with (some item in) its complement after a specifier has been merged. To see why this must be excluded, consider the following scenario: Suppose that a phase head $\gamma$ has been merged with some other category which becomes its complement, with one structure-building feature $[\bullet \mathrm{F} \bullet]$ remaining on $\gamma$ in the stack of structurebuilding features, and one probe feature $[* \mathrm{~F} *]$ remaining on $\gamma$ in the separate stack of probe features. For instance, $\mathrm{v}$ has been merged with VP, and now has a subcategorization feature $[\bullet D \bullet]$ left that will generate an external argument specifier, and a $[* \mathrm{acc} *]$ case feature (alternatively, a probe that captures a relevant bundle of $\phi$-features) on $v$ for Agree with an object DP in VP. Then, Agree(v, $\alpha$ in VP) (for accusative case assignment and $\phi$-feature agreement) must precede Merge $\left(\mathrm{DP}_{e x t}, \mathrm{v}^{\prime}\right)$ - if it did not, i.e., if the two operations were permitted to apply in reverse order, v would still be active (in the sense of the EFC in (9)) after the external argument DP has been merged, and could be provided with an edge feature attracting an item out of the external argument DP, to an outer specifier of v, after all. This would make it possible to avoid a PIC violation in the next step, and would thus undermine a derivation of the CED in (4) from the PIC. Therefore, it must be ensured that all probe features of a phase head are discharged before a specifier (with which the probe can never check a probe feature, given the first assumption) is introduced. Indeed, the ban against leaving probe features undischarged on a phase head follows without further ado, from a restrictive version of the Strict Cycle Condition (see Chomsky (1973)), as it is given in (20). ${ }^{21}$

(20) Strict Cycle Condition (SCC):

Within the current domain $\Gamma$, a binary syntactic operation may not exclusively apply to positions $\alpha, \beta$ if $\alpha$ and $\beta$ are both included within another domain $\Delta$ that is dominated by $\Gamma$.

Consequently, if a phase head $\gamma$ has an undischarged probe feature $[* \mathrm{~F} *]$ after it is merged with a category that becomes its specifier, no legitimate continuation of the derivation will be possible: If $[* \mathrm{~F} *]$ on $\gamma$ undergoes Agree with $\gamma$ 's specifier, the c-command requirement on Agree operations is violated; and if $[* \mathrm{~F} *]$ undergoes Agree with (an item within) $\gamma$ 's complement, the SCC is violated (within the projection of $\gamma$ that includes the specifier, such an Agree operation

\footnotetext{
21 The Strict Cycle Condition in (20) also rules out scenarios involving tucking in, as they are envisaged in Richards (2001); recall the discussion of (13).
} 
would exclusively apply to the lower projection of $\gamma$ that only includes $\gamma$ and its complement). ${ }^{22}$

In sum, the account of the (lexically determined) potential absence of barrier status with last-merged complements can be schematically depicted as in (21). Suppose that a phase head $\gamma$ (e.g., V) is merged with $\alpha$ (e.g., DP) and has thereby discharged all its structure-building features. The first possibility then is that edge feature insertion follows complement feature discharge, and there is no probe feature on the phase head. In this case, edge feature insertion violates clause (a) of the EFC (and if no edge feature can be inserted, subsequent extraction from the last-merged complement violates the PIC); see (21-a). Alternatively, edge feature insertion follows complement feature discharge, with a probe feature still present on the phase head, as in (21-b). This derivation violates nothing.

(21) Why last-merged complements do not have to be barriers:

a.

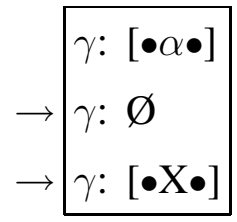

b.

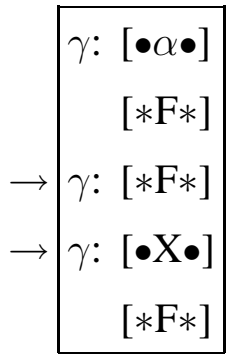

$\rightsquigarrow$ violates $(9-a)$

$\rightsquigarrow$ violates nothing

\footnotetext{
22 At this point, a remark may be due concerning the assumption that structure-building and probe features show up on separate stacks of a head, which I have adopted throughout this paper (cf. page 6). The alternative would be that the two feature types show up in a single hierarchy, in which case they would have to be interleaved: Probes can only be discharged after a complement has been merged, and before a specifier is merged, given the SCC; otherwise, the derivation would break down. However, there is a conceptual and an empirical problem with such a view. On the conceptual side, the order of the mixed classes of features on a single head would then have to be stipulated as a lexical property of the head even though it can be predicted from the interaction of the SCC and the fact that an Agree operation can only be carried out if there are two distinct categories involved (with one of them c-commanding the other). The two-stack approach avoids this redundancy. In addition, there is another, more pressing, empirical problem with the one-stack approach: A probe feature on a phase head that makes edge feature assignment to that phase head possible must be discharged before the derivationally assigned edge feature is discharged, for the reasons just discussed in the main text. But there is no way to derive this if there is only a single, mixed stack of features: An assigned edge feature would end up on top of the stack, above the probe feature, and the probe feature could then not be discharged before the specifier is introduced.
} 
Crucially, to avoid a SCC violation (as it would occur with specifiers), the probe feature must be discharged before the structure-building edge feature is discharged in (21-b) (and this is unproblematic given that the two features are on different stacks; see the last footnote).

The same reasoning as the one given here for last-merged complement DPs may also be relevant for projections of the clausal spine, which do not necessarily take specifiers. For instance, in German, there are clauses where VP, vP, TP, and CP all fail to be inherently equipped with structure-building features that generate a specifier. Still, as shown in (22), extraction from an object DP in VP may take place (here, the sole DP argument of an unaccusative verb stays in situ, and there is long-distance wh-extraction from the DP; see Grewendorf (1989) and Fanselow (2001a)).

(22) Worüber ${ }_{2}$ denkst du [CP $\mathrm{t}_{2}^{\prime \prime \prime \prime \prime \prime}$ dass $\left[\mathrm{TP} \mathrm{t}_{2}^{\prime \prime \prime \prime \prime}\left[{ }_{\mathrm{vP}} \mathrm{t}_{2}^{\prime \prime \prime \prime}\left[\mathrm{vP}_{2} \mathrm{t}_{2}^{\prime \prime \prime}\left[\mathrm{DP} \mathrm{t}_{2}^{\prime \prime}\right.\right.\right.\right.$ ein [NP $\mathrm{t}_{2}^{\prime}$ Buch $\left.\left.\left.\mathrm{t}_{2}\right]\right] \mathrm{t}_{V}\right]$ about what think you that a book erscheint-v ] T ] ] ?

appears

In (22), the projections of the clausal spine (CP, TP, vP, VP) can avoid barrier status if their heads undergo Agree relations with the minimally c-commanding head. Extending the concept of status-government introduced in Bech (1955/1957) in such a way that a clausal head statusgoverns the head of its verb complement, it is assumed in Sternefeld (1991) and Müller (1995) that such a status-government systematically removes barrier status from clausal projections in German (and other languages). In the studies just cited, status-government is modelled in terms of abstract incorporation (co-indexing of heads); in the present approach, this translates into Agree relations encoding the concept of status-government. Consequently, clausal projections are not barriers, even if there is no regular specifier present (and the projection is thus lastmerged). Exactly the same reasoning can be taken to apply for the structure of DPs (see, for instance, the D-N relation in (22)). Arguably, the difference between bridge verbs and nonbridge verbs can be modelled in the same way: A bridge verb (like denken ('think') in the German example (22)) may undero Agree with the head of its clausal complement CP; a nonbridge verb (like wissen ('know'), which gives rise to ungrammaticality if it replaces denken in (22)) may fail to be able to undergo Agree with the head of its CP sister. ${ }^{23}$

\footnotetext{
${ }^{23}$ If a C-T Agree relation were to fail to obtain in certain languages if $\mathrm{C}$ has certain properties, complementizertrace effects could possibly arise as consequences of a TP barrier (i.e., the impossibility of inserting an edge feature on C for an item in the edge domain of TP). See Koster (1986) and Müller (1995) for such an approach to complementizer-trace effects in languages like English. However, a bit more would have to be said under these assumptions to make non-subject movement across a lexical complementizer that possible. The more general question that arises in this context is how to account for differences between various types of categories with
} 
To sum up, the extended version of the present approach that takes into account probe features on phase heads makes some interesting, and largely correct, predictions. First, last-merged specifiers continue to be strict barriers. Second, last-merged complements are not barriers if the phase head has an additional probe feature for Agree with/into the complement; otherwise lastmerged complements are barriers. However, there is also a third prediction that I have not yet mentioned: Non-last-merged specifiers (i.e., non-first-merged items) and non-last-merged complements (i.e., first-merged items) are expected not to be barriers, independently of whether the phase head has appropriate probe features. Radical as though it may be, this prediction actually seems to be confirmed in many cases; see, e.g., the German examples in (23) (from Müller (1995), based on analogous Dutch data discussed in Koster (1987)). Here, a (non-argument) PP specifier of an unaccusative $\mathrm{V}$ is transparent for extraction (more specifically: topicalization) of an R-pronoun in the presence of a higher VP-internal specifier (the sole argument DP of the unaccusative verb); cf. (23-a). In contrast, the same (non-argument) PP specifier of an unergative $\mathrm{V}$ is a barrier for R-pronoun extraction (see (23-b)) because the sole argument DP is merged in Specv rather than in SpecV. ${ }^{24}$

(23) a. $\mathrm{Da}_{1}$ ist $\left[\mathrm{VP}_{\mathrm{V}}\right.$ er $\left[\mathrm{V}^{\prime}\left[\mathrm{PP}_{\mathrm{P}} \mathrm{t}_{1}\right.\right.$ mit $]\left[\mathrm{V}^{\prime}[\mathrm{PP}\right.$ zum Doktor $]$ gegangen $\left.]\right] \mathrm{v}$ there is he with to the doctor gone 'He went to the doctor with it.'

b. $* \mathrm{Da}_{1}$ hat $\left[\mathrm{vP}\right.$ er $\left[\mathrm{v}^{\prime}\left[\mathrm{vP}\left[\mathrm{PP}_{1}\right.\right.\right.$ mit $]\left[\mathrm{v}^{\prime}\right.$ das Rennen beendet $\left.\left.\left.]\right] \mathrm{v}\right]\right]$ there has he with the race finished 'He finished the race with it.'

Still, it is very well possible that this consequence may ultimately prove too far-reaching: For instance, certain accusative objects might be barriers despite the presence of a higher dative object. If so, this might be taken to suggest that the two objects do in fact show up in two distinct verbal projections, as has sometimes been argued.

\section{Freezing}

The approach developed so far predicts that last-merged specifiers that arise as a consequence of the lowest-ranked subcategorization feature on a phase head are barriers. At this point, the question arises of whether last-merged specifiers that come into existence because of a movementinducing (inherent) edge feature on a phase head are also barriers - and if so, whether this can

\footnotetext{
respect to island violations (subject vs. object, and argument vs. adjunct). I have nothing insightful to say about this issue here.

24 The difference between unaccusative $\mathrm{V}$ and unergative $\mathrm{V}$ presupposed here is independently motivated by a variety of tests, an immediately obvious one being perfect auxiliary selection - sein ('be') vs. haben ('have').
} 
be derived within the general theory adopted here. As for the empirical part, it seems fair to conclude that there is disagreement in the literature concerning the question of whether moved items (that have reached their final position) are always barriers for extraction to a higher position (i.e., whether there is a general freezing effect; cf., e.g., Ross (1967), Wexler \& Culicover (1980), Browning (1991), Collins (1994), and Rizzi (2006)); or whether in at least some cases, a moved item may stay (or, indeed, become) transparent for extraction (see, e.g., Chomsky (1986)). To give a few more specific examples: Whereas Cinque (1990) and Sternefeld (1991) argue that SpecC is invariably a barrier (even if the item moved to this position is transparent in situ), Chomsky (1986) and Lasnik \& Saito (1992) assume that SpecC is transparent for extraction (even if it is a barrier in situ). Similarly, Browning (1991), Collins (1994), Chomsky (1995), Rezac (2004), Broekhuis (2005), and Boeckx \& Grohmann (2007) (among many others) postulate that SpecT is a barrier; but Chomsky (2008), Gallego \& Uriagereka (2006), and Neeleman \& van de Koot (2007) suggest that this is not (or not always) the case. As for SpecC, Chomsky (1986) bases his assumption that SpecC is transparent on the Spanish data in (24-ab) (based on unpublished work by Esther Torrego), where it looks as though movement from a $w h$-moved subject is possible even though the subject is a barrier in situ. ${ }^{25}$

(24) a. *Esta es la autora $\left[\mathrm{PP}_{1}\right.$ de la que $]\left[\mathrm{DP}_{2}\right.$ varias traducciones $\left.\mathrm{t}_{1}\right]$ han ganado this is the author by whom various translations have won premios internacionales awards international

b. $\left({ }^{*}\right)\left[\mathrm{PP}_{1}\right.$ De que autora $]$ no sabes $\quad\left[\mathrm{CP}_{\left[\mathrm{DP}_{2}\right.}\right.$ que traducciones $\left.\mathrm{t}_{1}\right]$ han ganado $\mathrm{t}_{2}$ by what author not you know which translations have won premios internacionales ] ? awards international

Comparable judgments for analogous cases of extraction from SpecC in English are provided by Lasnik \& Saito (1992); see (25).

(25) a. ?? $\left.{ }^{*}\right) \mathrm{Who}_{1}$ do you wonder $\left[\mathrm{DP}_{2}\right.$ which picture of $\left.\mathrm{t}_{1}\right]$ Mary bought $\mathrm{t}_{2}$ ?

b. ??(*) $\mathrm{Who}_{1}$ do you wonder $\left[\mathrm{DP}_{2}\right.$ which picture of $\left.\mathrm{t}_{1}\right] \mathrm{t}_{2}$ is on sale ?

A set of examples used to argue for a transparency of SpecT in English given in Chomsky (2008) is (26-ab).

(26) a. $*\left[{ }_{\mathrm{PP}_{1}}\right.$ Of which car $]$ did $\left[\mathrm{DP}_{2}\right.$ the driver $\left.\mathrm{t}_{1}\right]\left[{ }_{\mathrm{vP}} \mathrm{t}_{1}\right.$ cause a scandal $]$ ? b. $(*)\left[\mathrm{PP}_{1}\right.$ Of which car $]$ is $\left[\mathrm{DP}_{2}\right.$ the driver $\left.\mathrm{t}_{1}\right]$ likely $\left[\mathrm{TP}_{2} \mathrm{t}_{2}^{\prime}\right.$ to $\mathrm{t}_{2}$ cause a scandal $]$ ?

\footnotetext{
${ }^{25}$ Here and in what follows, $(*)$ characterizes an example whose grammaticality status is disputed. In the context of the present discussion, $\left(^{*}\right)$ in (24), (25), and (26) stands for (relative, in (25)) wellformedness.
} 
Notwithstanding the empirical issue of what the correct empirical generalization is, the question can be raised what the approach developed so far predicts with respect to the presence or absence of CED effects in the context of (regular, non-intermediate) movement to specifier positions. As it stands, the prediction is clear enough: If nothing else is said, it follows from the present system that freezing effects can be avoided with complement movement (as in (25-a)), but not with movement of a specifier that is last-merged in its base position. Here is why complement movement is so far not predicted to create a freezing effect for extraction out of the complement: Suppose that $\alpha$ is a complement of $\mathbf{V}$, and in $\alpha$ 's edge position is a category $\beta$. Both $\alpha$ and $\beta$ are needed by categories $\gamma, \delta$ that have the appropriate movement-inducing structure-building features that recognize $\alpha$ and $\beta$ (alternatively, some item $\gamma$ is equipped with both features); $\gamma$ and $\delta$ are still part of the numeration on the VP cycle. Since inserting edge features to the phase head $\mathrm{V}$ at this point will thus have an effect on outcome (in the sense made precise in footnote 4), it is legitimate (if the phase head is not yet inert at the stage where assignment of an edge feature must take place). Consequently, $\beta$ can move out of $\alpha$ to SpecV, and $\alpha$ can also move to SpecV; the two movement steps can apply in any order, the only requirement being that the second movement goes beyond the landing site of the first movement (because of the SCC, which precludes tucking in). From this point on, the two items move hand in hand (but separately), to higher specifiers, until they reach their respective ultimate landing sites (see Heck (2004) for extensive discussion of derivations of this type). For last-merged specifiers, such a way of avoiding a barrier effect would not exist, however; when such a specifier has been basemerged with a phase head, the phase head invariably becomes inert, and no edge feature can be established on the phase head that might attract a specifier out of the last-merged specifier.

However, I do not take these predictions made by the present approach to be empirically correct; therefore, additional assumptions are called for. The empirical problem is that there are many well-established, entirely uncontroversial freezing effects. For instance, a topicalized VP is always a barrier blocking any kind of extraction ouf of VP in German; see (27) (from Müller (1998)): (27-a) illustrates VP topicalization; (27-b) illustrates ordinary wh-extraction from VP; and (27-c) shows that the two operations cannot be combined. Similarly, as observed by Postal (1972), a topicalized PP is a barrier for further extraction from PP in English; see (28): Postposition stranding becomes impossible under PP topicalization. And there are many more freezing effects of this type.

(27) a. Ich denke [CP [vP das Buch gelesen $]_{2}$ hat keiner $\left.t_{2}\right]$

I think the book read has no-one

b. [DP Was $]_{1}$ denkst du $\left[\mathrm{CP} \mathrm{t}_{1}^{\prime}\right.$ hat keiner $\left.\left[\mathrm{vP} \mathrm{t}_{1} \text { gelesen }\right]_{2}\right]$ ?

what think you has no-one read 
c. *[DP Was $]_{1}$ denkst du $\left[{ }_{\mathrm{CP}}\left[\mathrm{vP}_{\mathrm{p}} \mathrm{t}_{1} \text { gelesen }\right]_{2}\right.$ hat keiner $\left.\mathrm{t}_{2}\right]$ ? what think you gelesen has no-one

(28) a. $\mathrm{Who}_{1}$ do you think that he will talk $\left[\mathrm{PP}_{2}\right.$ to $\left.\mathrm{t}_{1}\right]$ ?

b. ${ }^{*} \mathrm{Who}_{1}$ do you think that $\left[\mathrm{PP}_{2}\right.$ to $\left.\mathrm{t}_{1}\right]$ he will talk $\mathrm{t}_{2}$ ?

Furthermore, closer scrutiny suggests that the putative exceptions to freezing in (24), (25), and (26) may to a significant extent be misanalyzed, and may not involve extraction from a moved item after all (the derivations involving extraction indicated above would then be ungrammatical). Thus, the exceptional examples tend to involve of-phrases (or their equivalents in other languages), which are known to be independently available as optional arguments in many cases. For instance, this is the only possibility in a German example like (29), which would otherwise have to involve long-distance scrambling from a finite clause in German (indicated here by " $\left(*_{1}\right)$ ") - an operation that is known to be strongly excluded, with no variation whatsoever involved (see Ross (1967), Müller \& Sternefeld (1993), Bayer \& Kornfilt (1994), Grewendorf \& Sabel (1994), and Fanselow (2001a), among others).

(29) dass ich [ $\mathrm{PP}_{1}$ von Peter ] glaube [CP dass $\left[\mathrm{DP}_{2}\right.$ eine neue CD $\left.\left(* \mathrm{t}_{1}\right)\right]$ erschienen ist ] that I of Peter believe that a new CD appeared is

A reanalysis of what may at first sight look like an instance of $o f$-phrase movement (with exceptional properties from the point of view of locality theory) as resulting from external Merge of an optional argument has been argued for with respect to constructions such as those in (24) and (26) by Koster (1987, 196f.), Cinque (1990, 47), Sternefeld (1991, 121), Müller (1995, 397f.), Barbiers $(2002,54)$, and Gallego $(2007,349)$ (the list is probably not exhaustive). I assume that this reanalysis is essentially correct (and that, in addition, data like those in (25) can be classified as ill formed). If so, (30) can be maintained as a valid empirical generalization (also cf. Rizzi (2006)). ${ }^{26}$

(30) Freezing Generalization:

A trace $t$ may not be included in a moved XP (i.e., an XP that binds a trace) if the antecedent of $\mathrm{t}$ c-commands XP.

\footnotetext{
${ }^{26}$ Barbiers $(2002,49)$ discusses a Dutch construction that looks like a good candidate for a genuine counterexample to (30); see (i), where $w h$-extraction from PP strands P in the matrix clause.

(i) Waar $_{1}$ had jij dan $\left[\mathrm{PP}_{2} \mathrm{t}_{1}\right.$ mee $]$ gedacht [CP dat je de vis $\mathrm{t}_{2}$ sou moeten snijden ] ?

where had you then with thought that you the fish would must cut

'What had you thought to be forced to cut the fish with?'

The account to be developed in this section will have nothing to say about the wellformedness if (i).
} 
(30) is formulated in such a way that it does not block traces in moved items (with the antecedent outside of the moved item) as such: Remnant movement configurations, where the antecedent eventually shows up in a lower position than the trace included in a moved XP, are permitted; remnant movement systematically exhibits an anti-freezing effect. ${ }^{27}$ Typical examples involving remnant VP topicalization in German are given in (31) (cf. Thiersch (1985), den Besten \& Webelhuth (1990), Grewendorf \& Sabel (1994), and Müller (1998)): A VP from which some item (here, $\mathrm{DP}_{1}$ ) has been scrambled subsequently undergoes topicalization, thereby producing an unbound trace. ${ }^{28}$

(31) a. $\left[\mathrm{VP}_{2} \mathrm{t}_{1} \mathrm{Zu}\right.$ lesen $]$ hat $\left[\mathrm{DP}_{1}\right.$ es ] keiner $\mathrm{t}_{2}$ versucht

to read has $\mathrm{it}_{a c c}$ no-one nom $_{\text {tried }}$

b. $\left[\mathrm{VP}_{2} \mathrm{t}_{1}\right.$ Gelesen $]$ hat der Fritz $\quad\left[\mathrm{DP}_{1}\right.$ das Buch $]$ nicht read has the Fritz ${ }_{n o m}$ the book $a c c$ not

As a first step towards deriving (30), let me make explicit some assumptions about movementinducing features. First, given that there are only two feature stacks associated with lexical items (viz., a stack of probe features and a stack of structure-building features), $[\bullet \mathrm{F} \bullet]$ features that trigger internal Merge are on the same stack as $\left[\bullet \mathrm{F}_{\bullet}\right]$ features that trigger external Merge. However, the former must be lower on the hierarchy - they become accessible only after all subcategorization features of a lexical item have been discharged. Next, suppose that movement-

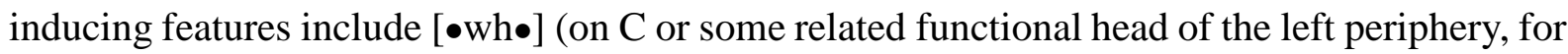
wh-movement); [॰top•] (on C or some related functional head of the left periphery, for topical-

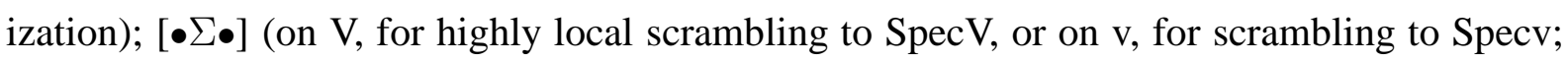

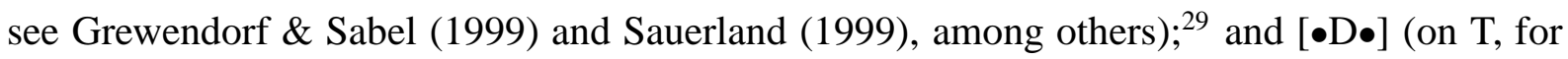
EPP-movement to SpecT). Against this background, I would like to suggest that multiple edge feature insertion follows a feature hierarchy going back to Williams (1974).

\footnotetext{
27 A side remark: Nothing in this paper forces a decision with respect to the question of whether movement leaves a trace, a full copy, or nothing at all. None of the primitive constraints adopted here (like the PIC, the EFC, or the SCC) refer to traces or copies; and where such items are referred to (as in the Freezing Generalization (30)), this is just for expository convenience.

${ }^{28}$ This analysis implies that restructuring (or 'coherent') infinitives as in (31-a) are bare VPs. See, e.g., Wurmbrand (2001).

${ }^{29}$ To simplify matters, I assume here that moved unstressed pronouns (i.e., 'object-shifted pronouns') and scrambled items both occupy a Specv position in German, triggered by $[\bullet \Sigma \bullet]$ on v. Since the two movement types behave differently in a number of respects (e.g., with respect to obligatoriness, order preservation, and interaction with optional subject raising triggered by an optional EPP feature on $\mathrm{T}$ in German), this may perhaps ultimately not prove correct. However, this question does not affect the issues currently under consideration.
} 
For concreteness, consider a derivation that has reached the stage indicated in (32), with WP a specifier of Z and ZP a complement of X (e.g., WP could be a DP of VP, and VP (= ZP) could be a complement of $v$, showing up to the left of $v$ in German; but (32) is more general, and the linearization options indicated here, although modelled on the concrete case just mentioned, are irrelevant for the discussion that follows). Suppose that both $\mathrm{WP}_{1}$ and $\mathrm{ZP}_{2}$ are phrases that will eventually (in the course of the derivation) be needed by movement-inducing features $[\bullet \mathrm{F} \bullet$ on lexical items that, at this point, are still part of the numeration. Then, $\mathrm{X}$ has to be provided with edge features that attract both $\mathrm{WP}_{1}$ and $\mathrm{ZP}_{2}$ to SpecX. This presupposes that $\mathrm{X}$ in (32) either has an undischarged structure-building feature or an undischarged probe feature left; let us assume the latter (as is indicated in (32)).

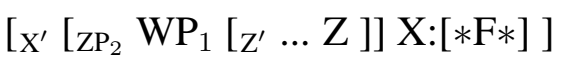

An important assumption that I would like to put forward here is that the assignment of the required edge features to $\mathrm{X}$ does not proceed in an unconstrained way; rather, there is a fixed order of edge feature insertion which follows a feature hierarchy that mirrors the typical hi-

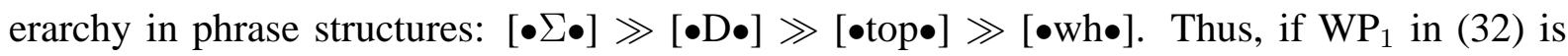
required by a lexical item (in the numeration) with a structure-building feature $\left[\bullet \mathrm{F}_{i} \bullet\right]$, and $\mathrm{ZP}_{2}$ in (32) is required by a lexical item (in the numeration) with a structure-building feature $\left[\bullet \mathrm{F}_{j} \bullet\right]$, and $\left[\bullet \mathrm{F}_{i} \bullet\right] \gg\left[\bullet \mathrm{F}_{j} \bullet\right]$, then the corresponding edge feature for $\mathrm{F}_{i}$ must be established first on $\mathrm{X}$, and $\mathrm{F}_{j}$ is assigned to $\mathrm{X}$ later (both in accordance with the EFC). Arguably, the simplest way to execute this idea is to give up the assumption that edge features assigned to phase heads in accordance with the EFC are category-neutral; thus, in what follows I assume that the edge feature assigned to a phase head identifies the category on which it is based. ${ }^{30}$ Suppose further that there is an additional condition stating that an edge feature cannot be inserted for a lower category $\mathrm{WP}_{1}$ after the insertion of an edge feature for a higher, more inclusive category $\mathrm{ZP}_{2}$ has been triggered. The two conditions are summarized in (33). ${ }^{31}$

\footnotetext{
${ }^{30}$ Still, category-sensitive edge features should presumably be kept distinct from movement-inducing features that are inherent to lexical items, so as to ensure that, e.g., there is no $w h$-movement from a target $w h$-position associated with an interrogative C (but see Reis \& Rosengren (1992) for a possible exception in German); however, accounts of effects like these would still be available if the distinction is not made.

31 See Grewendorf $(2003 ; 2004)$ and Abels (2006) for analyses of remnant movement asymmetries that incorporate a condition like (33-a) (and that either are, or could easily be made, compatible with the present approach); and Williams $(1974 ; 2003)$ and Sternefeld (1992) for the origins of the condition, which apparently was informally referred to as the 'Williams cycle' in Chomsky's 1974 MIT class lectures. Also note that (33-b) would follow from a minimal extension of the Strict Cycle Condition in (20). Thus, it is not inconceivable that (33-a) and (33-b) will
} 


\section{(33) Restrictions on multiple edge feature assignment:}

a. Multiple assignment of categorially marked edge features $\left[\bullet \mathrm{F}_{i} \bullet\right],\left[\bullet \mathrm{F}_{j} \bullet\right]$ to a single phase head respects the hierarchy $\left[\bullet \mathrm{F}_{i} \bullet\right] \gg\left[\bullet \mathrm{F}_{j} \bullet\right]$ (where $\left[\bullet \mathrm{F}_{j} \bullet\right]$ is intrinsically associated with a higher position in the clausal structure than $\left.\left[\bullet \mathrm{F}_{i} \bullet\right]\right)$.

b. An edge feature cannot be assigned to a head $\gamma$ for a category $\beta$ if an edge feature has been assigned to $\gamma$ for a category $\alpha$, and $\alpha$ includes $\beta$.

Returning to (32), assume first that $\mathrm{WP}_{1}$ is an item that qualifies as an $\mathrm{F}_{i}$-element (that will eventually be attracted by a lexical item bearing $\left[\bullet \mathrm{F}_{i} \bullet\right.$, which so far is still part of the numeration); that $\mathrm{ZP}_{2}$ is an item that qualifies as an $\mathrm{F}_{j}$-element (that will eventually be attracted by a lexical item bearing $\left.\left[\bullet \mathrm{F}_{j} \bullet\right]\right)$; and that $\left[\bullet \mathrm{F}_{i} \bullet\right] \gg\left[\bullet \mathrm{F}_{j} \bullet\right]$. The derivation of (32) can then be legitimately continued as in (34): Based on X's activity (due to the probe feature $[* \mathrm{~F} *]$, which is not yet discharged), the edge feature $\left[\bullet \mathrm{F}_{i} \bullet\right]$ is first added to $\mathrm{X}$; see (34-a). Assuming that feature checking obeys an earliness requirement (see Pesetsky (1989; 2000), Chomsky (2001)), $[* \mathrm{~F} *]$ is then discharged immediately in the next step, undergoing Agree with some goal in WP; see (34-b). Next, $\left[\bullet \mathrm{F}_{j} \bullet\right]$ is assigned to $\mathrm{X}$, ending up on top of the stack of structure-building features; see (34-c). This step is unproblematic because $\mathrm{X}$ is still active at this point, having received an edge feature in the last but one step (discharging $\left[\bullet \mathrm{F}_{i} \bullet\right]$ would have made this insertion impossible). In the fourth step, $\left[\bullet \mathrm{F}_{j} \bullet\right]$ is discharged, moving the $\mathrm{F}_{j}$-element $\mathrm{ZP}_{2}$ to a specifier of $X$ (an instance of string-vacuous movement that is needed nevertheless because it is the only way to satisfy the PIC on the cycle defined by the next phase head, given that $\mathrm{ZP}_{2}$ is initially a complement, hence, not part of the edge of $\mathrm{X})$; see $(34-\mathrm{d})$. Finally, $\left[\bullet \mathrm{F}_{i} \bullet\right]$ is discharged by moving the $\mathrm{F}_{i}$-element $\mathrm{WP}_{1}$ out of $\mathrm{ZP}_{2}$, to an outer specifier. As a consequence, the phase head has lost all its operation-inducing features, and the phase is completed; see (34-e).

(34) $\left[\mathrm{X}^{\prime}\left[\mathrm{zP}_{2} \mathrm{WP}_{1}\left[\mathrm{z}^{\prime} \ldots \mathrm{Z}\right]\right] \mathrm{X}:[* \mathrm{~F} *]\right]$
a. $\left[\mathrm{X}^{\prime}\left[\mathrm{ZP}_{2} \mathrm{WP}_{1}\left[\mathrm{Z}^{\prime} \ldots \mathrm{Z}\right]\right] \mathrm{X}:[* \mathrm{~F} *],\left[\bullet \mathrm{F}_{i} \bullet\right]\right]$
b. $\left[\mathrm{X}^{\prime}\left[\mathrm{ZP}_{2} \mathrm{WP}_{1}\left[\mathrm{Z}^{\prime} \ldots \mathrm{Z}\right]\right] \mathrm{X}:\left[\bullet \mathrm{F}_{i} \bullet\right]\right]$
c. $\left[\mathrm{X}^{\prime}\left[\mathrm{ZP}_{2} \mathrm{WP}_{1}\left[\mathrm{Z}^{\prime} \ldots \mathrm{Z}\right]\right] \mathrm{X}:\left[\bullet \mathrm{F}_{j} \bullet\right] \succ\left[\bullet \mathrm{F}_{i} \bullet\right]\right]$
d. $\left[\mathrm{X}^{\prime}\left[\mathrm{ZP}_{2} \mathrm{WP}_{1}\left[\mathrm{Z}^{\prime} \ldots \mathrm{Z}\right]\right]\left[\mathrm{X}^{\prime} \mathrm{t}_{2} \mathrm{X}:\left[\bullet \mathrm{F}_{i} \bullet\right]\right]\right]$
e. $\left[\mathrm{XP} \mathrm{WP}_{1}\left[\mathrm{x}^{\prime}\left[\mathrm{ZP}_{2} \mathrm{t}_{1}\left[\mathrm{Z}^{\prime} \ldots \mathrm{Z}\right]\right]\left[\mathrm{x}^{\prime} \mathrm{t}_{2} \mathrm{X}\right]\right]\right]$

This derivation respects all conditions, including the two restrictions on multiple edge feature assignment in (33-a) and (33-b). The continuation of this derivation is such that $\mathrm{WP}_{1}$ and $\mathrm{ZP}_{2}$

eventually both be derivable from a more general concept of cyclicity. For reasons of space and coherence, I will not pursue these issues here, though. 
move together through the next cycles (with edge feature assignment for $\mathrm{WP}_{1}$, viz., $\left[\bullet \mathrm{F}_{i} \bullet\right]$, preceding edge feature assignment for $\mathrm{ZP}_{2}$, viz., $\left[\bullet \mathrm{F}_{j} \bullet\right]$ on each phase head), until the ultimate landing sites associated with the lexical items are reached that bear the pertinent structurebuilding features as an inherent property. Given that $\left[\bullet \mathrm{F}_{i} \bullet\right]$ corresponds to a lower landing site in the phrase structure tree than $\left[\bullet \mathrm{F}_{j} \bullet\right.$, derivations of this type will create licit remnant movement configurations, such as those in (31) (where, e.g., $\left[\bullet \mathrm{F}_{i} \bullet\right]$ is $[\bullet \Sigma \bullet]$, and $\left[\bullet \mathrm{F}_{j} \bullet\right]$ is [॰top•], the $\mathrm{F}_{i}$-element $\mathrm{WP}_{1}$ is $\mathrm{DP}_{1}$, and the $\mathrm{F}_{j}$-element $\mathrm{ZP}_{2}$ is $\mathrm{VP}_{2}$ ).

In contrast to this, consider the ill-formed continuation of (32) in (35). Suppose that the only relevant difference is that this time, $\mathrm{ZP}_{2}$ is the $\mathrm{F}_{i}$-element (i.e., the item that must be moved to the specifier of the phase so as to provide an accessible element for subsequent movement to the specifier of a lexical item inherently bearing $\left.\left[\bullet \mathrm{F}_{i} \bullet\right]\right)$, and $\mathrm{WP}_{1}$ is the $\mathrm{F}_{j}$-element. In this case, a dilemma arises because (33-a) and (33-b) cannot both be fulfilled. (33-a) demands that $\left[\bullet \mathrm{F}_{i} \bullet\right]$ is inserted as the next step in (35), as in (34); see (35-a) (if $\left[\bullet \mathrm{F}_{j} \bullet\right]$ is assigned first, the derivation breaks down immediately). Probe feature discharge in (35-b) is unproblematic. However, any continuation of $(35-\mathrm{b})$ will now run into problems. It is clear that $\left[\bullet \mathrm{F}_{j} \bullet\right]$ would have to be added next, and that this feature would have to go the top of the feature stack on $\mathrm{X}$ (given the EFC), as in (35-c). However, given that $\left[\bullet \mathrm{F}_{j} \bullet\right]$ corresponds to $\mathrm{WP}_{1}$ in this case (which is the $\mathrm{F}_{j}$-element), and $\mathrm{WP}_{1}$ is included in $\mathrm{ZP}_{2}$ at this point, such an assignment of an edge feature invariably violates (33-b). Consequently, $\left[\bullet \mathrm{F}_{j} \bullet\right]$ cannot be assigned to $\mathrm{X}$, and $\mathrm{WP}_{1}$ cannot move out of $\mathrm{ZP}_{2}$ on the XP cycle. Furthermore, given that edges are defined nonrecursively (cf. footnote 13), such that the edge $\beta$ of an edge $\alpha$ of a phase $\Gamma$ is not part of the edge of $\Gamma$, the PIC ensures that $\mathrm{WP}_{1}$ will not be able to move out of $\mathrm{ZP}_{2}$ at any subsequent step of the derivation either.

(35) $\left[\mathrm{x}^{\prime}\left[\mathrm{ZP}_{2} \mathrm{WP}_{1}\left[\mathrm{Z}^{\prime} \ldots \mathrm{Z}\right]\right] \mathrm{X}:[* \mathrm{~F} *]\right]$
a. $\left[\mathrm{X}^{\prime}\left[\mathrm{ZP}_{2} \mathrm{WP}_{1}\left[\mathrm{Z}^{\prime} \cdots \mathrm{Z}\right]\right] \mathrm{X}:[* \mathrm{~F} *],\left[\bullet \mathrm{F}_{i} \bullet\right]\right]$
b. $\left[\mathrm{X}^{\prime}\left[\mathrm{ZP}_{2} \mathrm{WP}_{1}\left[\mathrm{Z}^{\prime} \ldots \mathrm{Z}\right]\right] \mathrm{X}:\left[\bullet \mathrm{F}_{i} \bullet\right]\right]$
c. $*\left[\mathrm{X}^{\prime}\left[\mathrm{zP}_{2} \mathrm{WP}_{1}\left[\mathrm{Z}^{\prime} \ldots \mathrm{Z}\right]\right] \mathrm{X}:\left[\bullet \mathrm{F}_{j} \bullet\right] \succ\left[\bullet \mathrm{F}_{i} \bullet\right]\right]$

Thus, freezing effects like those in $(26)$ are accounted for. Here, $\left[\bullet \mathrm{F}_{i} \bullet\right]$ is $[\bullet \mathrm{D} \bullet]$ (i.e., the EPP

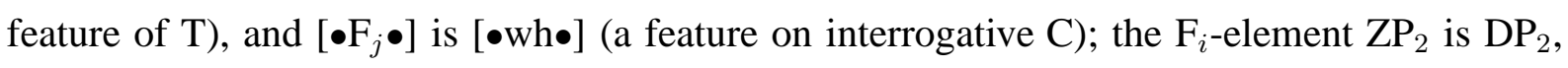
and the $\mathrm{F}_{j}$-element $\mathrm{WP}_{1}$ is $\mathrm{PP}_{1}\left(\mathrm{PP}_{1}\right.$ must have undergone edge-feature driven movement to the edge of $\mathrm{DP}_{2}$ first because of the PIC). Similar reasonings apply to all instances of freezing effects where two different movement types are involved (e.g., (24-a) in Spanish, if raising is involved here). For freezing effects where two identical structure-building features occur (as in (24-b) in Spanish and (25) in English), a minimal extension of what has been suggested so 
far is required: It suffices to assume that there is an addition to (33-a) such that in cases of identical structure-building features, the higher, more inclusive category must be targetted first; insertion of an identical feature for a second category dominated by the first one is then always impossible, because of (33-b).$^{32}$

To sum up this section, it has turned out that whereas the present approach (which centers around the assumption that edge feature insertion is possible only as long as a head can in principle drive operations, and has not yet become inert) fully succeeds in deriving CED effects with externally (last-) merged specifiers from the PIC, a bit more must be said to ensure that all internally (last-) merged specifiers are barriers, too (unless certain kinds of remnant movement are involved). To achieve this result, I have adopted the two restrictions on multiple edge feature insertion in (33), both of which seem natural; moreover, both restrictions can arguably be viewed as independently motivated extensions of the Strict Cycle Condition (see footnote 31).

Interestingly, the present approach may have to depend on additional assumptions to derive freezing, but it automatically (and in the simple, non-extended form sketched in sections 2-3) predicts a reverse phenomenon that I call melting.

\section{Melting}

There is a suprising further effect that is predicted under the system of assumptions laid out in sections 2-3: A specifier $\alpha$ of a phase $\Gamma$ that is normally (i.e., if it is last-merged in its projection) an island for extraction should "melt", i.e., cease to be a barrier when some $\beta$ becomes an outer specifier of $\Gamma$ by movement to a higher position within the same phase. To the best of my knowledge, melting has not yet been discussed as a natural class of phenomena in the literature; but the effect seems real enough.

A melting effect can be observed with highly local movement (viz., scrambling) in front of base-merged argument DPs in languages like German and Czech.

\footnotetext{
32 The present approach does not simply draw the line between freezing effects with bound traces, and an absence of freezing effects with unbound traces (i.e., remnant movement). Remnant movement constructions of the type in (i-ab) (see Takano (1994), Grewendorf \& Sabel (1994), Kitahara (1997), and Müller (1998)) are also correctly excluded.

(i) a. *dass $\left[\mathrm{VP}_{2} \mathrm{t}_{1} \mathrm{zu}\right.$ lesen $]$ es ${ }_{1}$ keiner $\mathrm{t}_{2}$ versucht hat that to read it no-one tried has

b. *dass $\left[\mathrm{VP}_{2} \mathrm{t}_{1}\right.$ gelesen $]$ der Fritz das Buch nicht $_{2}$ hat that read the Fritz the book not has

These examples differ minimally from those in (31) in that $\mathrm{VP}_{2}$ and $\mathrm{DP}_{1}$ are moved because of the same structurebuilding feature (viz., $[\bullet \Sigma \bullet])$.
} 


\subsection{Melting effects with scrambling in German}

Consider first melting effects with scrambling in German. In (36-ab), it is shown that one and the same subject DP is a barrier for was für ('what for') split if it precedes an object DP, but becomes transparent for extraction of was if the object DP undergoes local scrambling in front of the subject. ${ }^{33}$

(36) a. $* \mathrm{Was}_{1}$ haben $\left[\mathrm{DP}_{3} \mathrm{t}_{1}\right.$ für Bücher $]\left[\mathrm{DP}_{2}\right.$ den Fritz ] beeindruckt? what have for books ${ }_{n o m}$ the Fritz ${ }_{a c c}$ impressed

b. Was ${ }_{1}$ haben $\left[\mathrm{DP}_{2}\right.$ den Fritz $]\left[\mathrm{DP}_{3} \mathrm{t}_{1}\right.$ für Bücher $] \mathrm{t}_{2}$ beeindruckt ? what have the Fritz acc $_{\text {for books }}$ impressed

The same kind of melting effect with subject DPs created by local object scrambling to a position in front of the subject shows up with extraction of a PP; see (37-a) (with subject and object both in situ) vs. (37-b) (with local object scrambling).

(37) a. $*\left[\mathrm{PP}_{1}\right.$ Über wen $]$ hat $\left[\mathrm{DP}_{3}\right.$ ein Buch $\left.\mathrm{t}_{1}\right]\left[\mathrm{DP}_{2}\right.$ den Fritz $]$ beeindruckt ? about whom has a book $_{n o m}$ the Fritz $a c c$ impressed

b. $\left[\mathrm{PP}_{1}\right.$ Über wen $]$ hat $\left[\mathrm{DP}_{2}\right.$ den Fritz $]\left[\mathrm{DP}_{3}\right.$ ein Buch $\left.\mathrm{t}_{1}\right] \mathrm{t}_{2}$ beeindruckt? about whom has the Fritz $a c c$ a book

The empirical evidence seems fairly uncontroversial. The data have been checked with a number of native speakers; and, as mentioned above, examples of the type in (36-b) and (37-b) have figured prominently in approaches that strive to classify subject DPs as transparent for extraction in German even in constructions which are neither unaccusative nor passive (see footnote 17).

The analysis of melting effects is straightforward. First, recall that I have assumed that scrambling is feature-driven: It is an operation triggered by designated structure-building features $[\bullet \Sigma \bullet]$ on $\mathrm{V}$ or $\mathrm{v}$; only the latter option is relevant in cases of scrambling to a position in front of agentive subject arguments in situ, i.e., Specv. Second, suppose that v still has a movement-inducing feature $[\bullet \Sigma \bullet]$ left on the stack of structure-building features after discharge of its final subcategorization feature $[\bullet \mathrm{D} \bullet$ ] (which has triggered external Merge of the subject DP). Thus, the phase head $\mathrm{v}$ is still active at this point of the derivation, and an edge

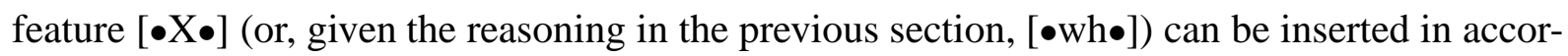

\footnotetext{
33 As shown by Grewendorf (1989) on the basis of a number of tests, a psych verb like beeindrucken ('impress') takes a regular external argument in German; i.e., the nominative DP here is never VP-internal. (As a matter of fact, one of the ten or so tests employed in that work is based on extraction from DP, as in (36-a); see Grewendorf (1989, 182).) However, it may be worth pointing out that the pattern in (36) would be identical if Bücher ('books') were to be replaced with Leute ('people'), and beeindruckt ('impressed') with the agentive, non-psych verb getroffen ('met').
} 
dance with the EFC before the phase is complete. Third and finally, this implies that the phase head v can now attract an item out of the external argument in the inner Specv position to an outer specifier, and thereby ensure that this item is accessible for further movement as part of the edge of the phase (given the PIC). As in the derivations discussed in section 3 (cf. (13) in particular), it follows from the phase heads' last-in/first-out property that the item extracted out of the subject must land in a specifier position that is lower than the position of the scrambled object (but, of course, within the same XP). The relevant part of the derivation (focussing on the vP domain) is shown for a melting example like (37-b) in (38) (where $\mathrm{DP}_{2}$ is the scrambled object argument, and $\mathrm{DP}_{3}$ is the subject argument in its base position).

(38) $\underline{\mathrm{PP}_{1}} \ldots\left[\mathrm{vP}_{\mathrm{vP}}\left[\mathrm{ve}_{\mathrm{v}^{\prime}} \underline{\mathrm{t}_{1}^{\prime \prime}}\left[\mathrm{v}^{\prime}\left[\mathrm{DP}_{3} \underline{\mathrm{t}_{1}^{\prime}} \ldots \underline{\mathrm{t}_{1}}\right]\left[\mathrm{v}^{\prime}\left[\mathrm{vP} \ldots \mathrm{t}_{2} \ldots \mathrm{V}\right] \mathrm{v}\right]\right]\right]\right]$

(39) illustrates schematically how the stack of structure-building features associated with a phase head $\gamma$ in a melting derivation changes, and is eventually reduced to zero. As before, $[\bullet \beta \bullet]$ creates the complement of the phase head, and $[\bullet \alpha \bullet]$ creates the specifier. However, by assumption, the phase head also has a movement-inducing feature $[\bullet \delta \bullet]$ (the scrambling feature $[\bullet \Sigma \bullet]$, in the case just discussed - also recall from the previous section that features that trigger internal Merge are initially ranked below features that trigger external Merge on a lexical item),

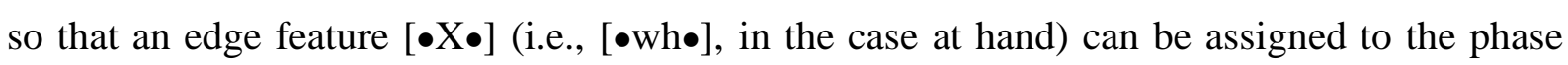
head that extracts an item out of the specifier without inducing a CED effect.

(39) How the melting effect is derived:

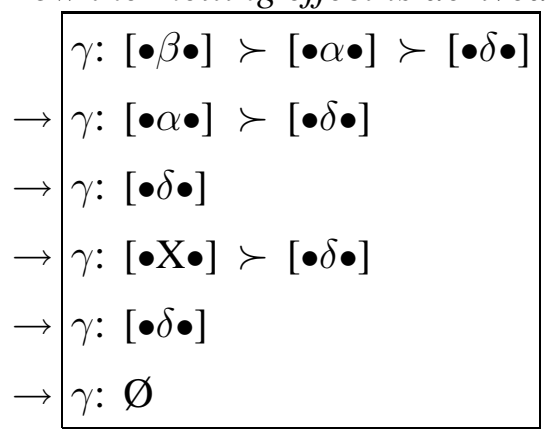

$\rightsquigarrow$ violates nothing

The important difference to typical CED effects with subject DPs is that in (39), the feature that introduces the subject DP (viz., [• $[\bullet]$ ) is not the lowest-ranked feature on the stack of structurebuilding features; so the phase head is still active once this feature is discharged, and can be targetted by edge feature insertion, which may then extract some item out of the subject DP's edge domain.

Given this approach, we expect that the same effect should also arise in double object constructions: A nominative DP externally merged in Specv should undergo melting and become transparent for extraction if a dative DP (indirect object) is scrambled in front of it, even if 
the accusative DP (direct object) stays in situ, in the VP. As shown in (40-a) vs. (40-b), this prediction is borne out.

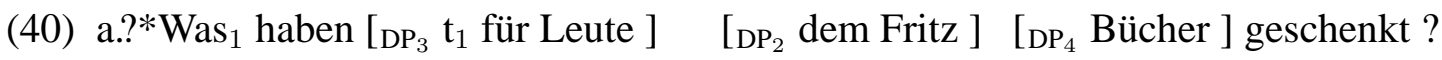
what have for people nom $_{\text {for }}$ the Fritz dat $_{\text {books }}$ given

b. Was ${ }_{1}$ haben [ $\mathrm{DP}_{2}$ dem Fritz $] \quad\left[\mathrm{DP}_{3} \mathrm{t}_{1}\right.$ für Leute $] \mathrm{t}_{2}\left[\mathrm{DP}_{4}\right.$ Bücher $]$ geschenkt ? what have the Fritz $_{d a t}$ for people ${ }_{n o m}$ books ${ }_{a c c}$ given

(40-b) is particularly interesting because it shows that the melting effect is not an adjacency effect - as a result of indirect object scrambling to Specv in (40-b), the subject and the verb do not become adjacent because the direct object still intervenes. Thus, V adjacency may sometimes be a side effect of melting, but it is irrelevant as such.

Finally, the present analysis also predicts that local (VP-internal) scrambling of the direct object to a position in front of the indirect object should give rise to melting of the indirect object; as shown in (41-a) (with the direct object in situ) vs. (41-b) (with a locally scrambled direct object), this is the case.

(41) a. $* W^{2} s_{1}$ hat er $\quad\left[\mathrm{DP}_{3} \mathrm{t}_{1}\right.$ für Leuten $]\left[\mathrm{DP}_{2}\right.$ den Fritz $]$ vorgestellt ? what has he nom $_{\text {nople }}$ for the Fritz acc $_{\text {introduced }}$

b. Was 1 hat er $\left[\mathrm{DP}_{2}\right.$ den Fritz $]\left[\mathrm{DP}_{3} \mathrm{t}_{1}\right.$ für Leuten $] \mathrm{t}_{2}$ vorgestellt? what has he $\mathrm{n}_{\text {nom }}$ the Fritz focc $_{\text {foople }}$ fat introduced

To sum up so far, it is correctly predicted that local scrambling to a position in front of a specifier that would otherwise be last-merged in its phase creates a melting effect in German: The specifier becomes transparent for extraction.

\subsection{Melting effects with scrambling in Czech}

The same phenomenon shows up in Czech; it can be seen very clearly in DP split constructions (see Fanselow \& Lenertová (2007) and Kučerová (2006) for recent discussion), but also with other instances of movement from DP. The analysis that suggests itself for this effect is essentially identical to that given for German (assuming that Czech scrambling of the type shown here targets Specv); the different position of the verb is irrelevant. ${ }^{34}$

Consider DP split constructions first. (42-ab) show that whereas the subject DP žádná stará ('the old (one)', with a missing noun) is a barrier for extraction of the adjective stará, it becomes transparent when the accusative object Petra ('Peter') is locally scrambled in front of it; (42-b)

\footnotetext{
${ }^{34}$ Data and original judgements in this subsection are due to Petr Biskup and Denisa Lenertová; the judgements have been confirmed by Pavel Caha and Ivona Kučerová.
} 
may not be fully well formed, but it is perceived as a drastic improvement over (42-a). ${ }^{35}$

(42) a. *Stará ${ }_{1}$ neudeřila $\left[D_{3}\right.$ žádná $\left.t_{1}\right]$ Petra $_{2}$

old $_{\text {nom }}$ hit $\quad$ no $_{\text {nom }} \quad$ Petr $_{a c c}$

'No old one hit Petr.'

b.(?)Stará 1 neudeřila Petra 2 [DP 3 žádná $\left.\mathrm{t}_{1}\right] \mathrm{t}_{2}$

old $_{\text {nom }}$ hit Petr $_{a c c} \quad$ no $_{\text {nom }}$

'No old one hit Petr.'

The same kind of melting effect with splits taking place from subject DPs can be seen in (43). In (43-a), holka ('girl') is moved from a subject DP, stranding žádná ('no'), while both subject and object are in their canonical positions. In (43-b), local object scrambling makes the subject transparent for extraction; the result has the same status as instances of extraction from the object DP itself; see (43-c). ${ }^{36}$

(43) a. * $\left[\mathrm{NP}_{1}\right.$ Holka ] neudeřila [ $\left[\mathrm{DP}_{3}\right.$ žádná $\left.\mathrm{t}_{1}\right]$ Petra $_{2}$ girl $_{\text {nom }}$ hit no $_{\text {nom }}$ Petr $_{a c c}$

'No girl hit Petr.'

b. $\quad\left[\mathrm{NP}_{1}\right.$ Holka $]$ neudeřila Petra $2{ }_{\mathrm{DP}_{3}}$ žádná $\left.\mathrm{t}_{1}\right] \mathrm{t}_{2}$ girl $_{\text {nom }}$ hit Petr ${ }_{a c c} \quad$ no $_{\text {nom }}$ 'No girl hit Petr.'

c. $\left[\mathrm{NP}_{1} \mathrm{Holku}\right]$ neudeřil Petr $2 \quad\left[\mathrm{DP}_{3}\right.$ žádnou t 1 ] $\operatorname{girl}_{a c c}$ hit Petr ${ }_{n o m} \quad$ no $_{a c c}$

'Petr hit no girl.'

Turning next to cases of PP extraction from DP (as an instance of topicalization), the examples in (44) show the same kind of subject DP melting that we have just seen with DP split constructions. (44-c) involves extraction from an object DP, which is possible; (44-a) illustrates the fact that extraction from a subject DP is not possible if both subject and object occupy their base positions; and (44-b) is again a case of melting: The subject DP ceases to be a barrier for extraction when the object DP is scrambled in front of it.

(44) a. $*\left[\mathrm{PP}_{1} \mathrm{O} \quad\right.$ starých autech $]$ oslovila $\left[\mathrm{DP}_{3} \mathrm{knihat}_{1}\right]$ Petra 2 about old cars fascinated book nom $_{\text {Petr }}$ acc

\footnotetext{
35 I assume here that DP split constructions in Czech are derived by regular movement of the displaced item, not by some combination of copy movement plus deletion (as, e.g., in Fanselow \& Ćavar (2001)), or by base-generation. The very fact that CED effects can be noted here would seem to lend strong support to this view (in contrast to what we have seen with DP split constructions in German; see footnote 17).

${ }^{36}$ Based on work by Beck (1997) and Pesetsky (2000), Kučerová (2006) identifies intervention and antiintervention effects in DP split constructions in Czech. All the examples in this subsection are constructed in such a way (e.g., by avoiding certain verb placements) that this potentially interfering issue does not arise.
} 
'A book about old cars fascinated Petr.'

b.(?) $\left[\mathrm{PP}_{1} \mathrm{O} \quad\right.$ starých autech ] oslovila $\mathrm{Petra}_{2}\left[\mathrm{DP}_{3} \mathrm{kniha}_{1}\right] \mathrm{t}_{2}$ about old cars fascinated Petr acc $_{\text {book }}$ nom

'A book about old cars fascinated Petr.'

c. $\left[\mathrm{PP}_{1} \mathrm{O}\right.$ starých autech $]$ četl $\mathrm{Petr}_{2} \quad\left[\mathrm{DP}_{3} \mathrm{knihu} \mathrm{t}_{1}\right]$ about old cars read Petr nom $_{\text {book }}$ acc 'Petr read a book about old cars.'

Finally, the same pattern emerges with wh-movement from DP. As is well known, such extraction may violate the Left Branch Condition in various Slavic languages; I will have nothing to say about this here. Extraction of čí ('whose') from an object DP is possible (see (45-cd), with variable positioning of the verb); in contrast, extraction of či from a subject DP is impossible (see $(45-a)$ ) - unless, that is, the object is scrambled across the subject, as in (45-b). ${ }^{37}$

(45) a. *Č́́ $i_{1} \quad$ udeřila $\left[\mathrm{DP}_{3} \mathrm{t}_{1}\right.$ sestra $] \operatorname{Petra}_{2} \mathrm{t}_{2}$ ?

whose hit sister $_{\text {nom }}$ Petr $_{a c c}$

'Whose sister hit Petr?'

b. $(*) \check{C}_{1} i_{1} \quad$ udeřila Petra $2\left[\mathrm{DP}_{3} \mathrm{t}_{1}\right.$ sestra $] \mathrm{t}_{2}$ ?

whose hit Petr $_{a c c} \quad$ sister $_{n o m}$

'Whose sister hit Petr?

c. Č́ $i_{1} \quad$ udeřil Petr $\left[\mathrm{DP}_{3} \mathrm{t}_{1}\right.$ sestru ]?

whose hit Petr nom $_{\text {sister }}$ acc

'Whose sister did Petr hit?'

d. Č́́ $i_{1}$ Petr udeřil [DP $\mathrm{DP}_{3}$ sestru ] ?

whose Petr nom $_{\text {nit }}$ hister

'Whose sister did Petr hit?'

Thus, the Czech data illustrate the same pattern as the German data in the previous section: Local scrambling creates a melting effect. Interestingly, the Czech examples differ from the German examples with respect to the position of the verb. In all the cases listed here (except for (45-d)), the verb precedes both subject and object. ${ }^{38}$ Since extraction from the subject is only possible when the object is scrambled, and as a result comes to separate the verb and the subject, the conclusion arrived at on the basis of data like (40-b) in German is reinforced: The melting effect (as it can be seen with subjects in German) cannot be reduced to an adjacency effect.

\footnotetext{
${ }^{37}$ It should be noted, however, that the contrast may not be as crystal-clear as those discussed before, as indicated by (*) in (45-b).

${ }^{38}$ Of course, the question arises which position $\mathrm{V}$ occupies in these cases. It seems clear that $\mathrm{V}$ has undergone movement here, but what exactly the nature of the landing site is does not seem to be important for present purposes, so I will leave this issue unresolved.
} 


\subsection{Further Issues}

The present approach differs from other theories of locality with a focus on CED effects in that it envisages the possibility that some XP $\alpha$ may or may not be a barrier in two syntactic contexts that do not differ with respect to the relation between $\alpha$ and the surrounding heads of the clausal projection. Thus, I have assumed so far that $\mathrm{DP}_{3}$ in (36), (37), (40), and (41) in German occupies exactly the same position in the (a)-examples and in the (b)-examples; and the same goes for (the subject) $\mathrm{DP}_{3}$ in the Czech examples (42), (43), (44), and (45). Nevertheless, $\mathrm{DP}_{3}$ qualifies as a barrier if it is last-merged in $\mathrm{vP}$, but becomes transparent by local scrambling of some item to an immediately preceding position in $\mathrm{vP}$ (the melting effect). If the structural position of $\mathrm{DP}_{3}$ itself is identical throughout, the differences with respect to extraction options do not seem to be accountable for under standard approaches to the CED for principled reasons. Consider, for instance, the classical approach to CED effects in a pre-minimalist setting: XP is a barrier iff it is not L-marked by an appropriate head (as in Chomsky (1986), Cinque (1990), and much related work). If the relations between the potentially relevant heads $(\mathrm{C}, \mathrm{T}, \mathrm{v}, \mathrm{V})$ and $\mathrm{DP}_{3}$ are identical in all the German examples in (36), (37), (40), and (41), $\mathrm{DP}_{3}$ should either uniformly qualify as a barrier, or it should uniformly be transparent; and the same goes for the Czech examples in the previous subsection. Similar conclusions apply in the case of more recent, minimalist reconstructions of CED effects (cf. the literature mentioned in footnote 1). Therefore, if it can be shown that $\mathrm{DP}_{3}$ occupies identical positions in the (a)-examples and in the (b)-examples, this can be taken as direct support for the present analysis.

Indeed, all available evidence points in this direction. To give an example (and focussing on German), topicalization of V plus object DP (stranding a subject DP) typically yields wellformed results in German, whereas topicalization of V plus subject DP (stranding an object DP) does not. Thus, the generalization suggests itself that VP can undergo topicalization whereas vP cannot undergo topicalization (at least not as easily; see Haider (1993) for a few, systematically classifiable counter-examples). For present purposes, we may ignore the question of what accounts for this generalization (and how the putative exceptions are treated); it may suffice to note that the examples in (46) instantiate this contrast.

(46) a. * $\left[{ }_{\mathrm{vP}_{2}}\left[\mathrm{DP}_{3}\right.\right.$ Ein Buch $] \mathrm{t}_{1}$ beeindruckt $]$ hat $\mathrm{ihn}_{1}$ nicht $\mathrm{t}_{2}$

a book $_{n o m}$ impressed has him acc $_{\text {not }}$

b. $\left[\mathrm{VP}_{2}\left[\mathrm{DP}_{3}\right.\right.$ Ein Buch $]$ gelesen $]$ hat $\mathrm{er}_{1}$ nicht $\mathrm{t}_{2}$

a book $_{a c c}$ read has he ${ }_{\text {nom }}$ not

As shown in (47), this contrast is maintained in those cases where wh-extraction from $\mathrm{DP}_{3}$ has taken place. Here, wh-extraction from $\mathrm{DP}_{3}$ (subject in (47-a), object in (47-b)) to the embedded SpecC position is followed by long-distance topicalization of $\mathrm{V}+\mathrm{DP}_{3}$. This involves a remnant 
movement configuration. However, the configuration is legitimate as such (abstracting away from a weak wh-island effect that cannot be avoided; see Fanselow (1987)); in particular, no constraints on remnant movement are violated (see Müller (1998)). Therefore, the fact that (47-a) is ungrammatical strongly suggests that $\mathrm{DP}_{3}$ does not show up in a lower, VP-internal position even if $w h$-extraction has taken place, and a melting effect due to object fronting cannot be excluded. ${ }^{39}$

(47) a. $*{ }_{\mathrm{vP}_{2}}\left[\mathrm{DP}_{3}\right.$ Ein Buch $\left.\mathrm{t}_{1}\right] \mathrm{t}_{4}$ beeindruckt $]$ weiß ich nicht $\left[\mathrm{CP}_{\mathrm{CP}}\left[\mathrm{PP}_{1}\right.\right.$ über wen $] \mathrm{ihn}_{4}$ $\mathrm{t}_{2}$ hat ] a book nom $_{\text {impressed know I now about whom him }}$ acc has

b. ?? $\left[\mathrm{VP}_{2}\left[\mathrm{DP}_{3}\right.\right.$ Ein Buch $\left.\mathrm{t}_{1}\right]$ gelesen $]$ weiß ich nicht [CP [ ${ }_{\mathrm{PP}_{1}}$ über wen $] \mathrm{er}_{4} \mathrm{t}_{2}$ hat $]$ a book read know I not about whom he has

I thus take it to be uncontroversial that subject DPs in German (i.e., nominative DPs in constructions that are neither unaccusative nor passive) never show up VP-internally. ${ }^{40}$

The remaining alternative is that the subject DPs (labelled $\mathrm{DP}_{3}$ ) in (36), (37), and (40) are in Specv in the well-formed cases, and in SpecT in the ill-formed cases; and that the theory of locality is then somehow sensitive to this difference. However, such an account does not seem viable either. The first thing to note is that whereas there is good evidence that the subject DP is within vP in examples like (36-b) (given that scrambling in German cannot target a domain beyond $\mathrm{vP}$ ), there is no evidence whatsoever that the subject DP has undergone optional raising to SpecT in ungrammatical (non-melting) examples like (36-a); indeed, from a theory-internal point of view, it is hard to see what could force (string-vacuous) subject raising to SpecT in (cases like) (36-a) while (at least optionally) blocking it in (cases like) (36-b).

Second, Webelhuth (1992), Diesing (1992), Haider (1993) and others have proposed that certain items (like the particles ja, doch, denn, etwa) demarcate (what is in current terminology)

\footnotetext{
39 As a matter of fact, the illformedness of (46-a) might already suggest the same thing (depending on further assumptions).

${ }^{40}$ Note that this is the main reason for excluding a version of the present analysis according to which scrambling does not involve movement, but is rather due to an operation of subcategorization feature reversal in the lexicon, as envisaged by Haider (1988) and Fanselow (2001a) for German. On such a view, a "scrambled" object would be externally merged above the subject, and this would then also account for the melting effect. I do not adopt such an analysis for various reasons here (having to do with what still strikes me as significant evidence for scrambling as movement in German, despite the arguments to the contrary given in Fanselow (2001a)), independently of the issue just discussed in the text. However, these considerations notwithstanding, it is at least worth bearing in mind that there is no principled incompatibility of a scrambling-as-base generation approach with the analysis of CED effects suggested in the present paper.
} 
the vP edge. Suppose that this is the case (for base generation; see below). It can then be noted that the addition of a particle preceding the subject DP does not improve extraction from the subject DP in the examples that do not involve local object scrambling; on the other hand, the melting examples stay well formed. See (48-a) vs. (48-bc), and (48-d) vs. (48-ef). This state of affairs implies that the barrier status of subject DPs in German discussed so far uniformly involves Specv, which confirms the reality of the melting effect. It also implies that particles like denn and wohl either do not enter the syntactic derivation via structure-building features, or fail to be part of the vP proper. I will assume the former because the examples in (48-cf), with object scrambling to a position in front of the particle, are well formed; given that scrambling is confined to the vP/VP domain in German, this implies that the particles in question may demarcate the vP edge before movement, but do not have to show up at the left phonological border of vP after scrambling has applied. ${ }^{41}$

(48) a. *Was ${ }_{1}$ haben denn $\left[\mathrm{DP}_{3} \mathrm{t}_{1}\right.$ für Bücher ] [ $\mathrm{DP}_{2}$ den Fritz ] beeindruckt ? what have PRT for books ${ }_{n o m}$ the Fritz ${ }_{a c c}$ impressed

b. Was ${ }_{1}$ haben denn $\left[\mathrm{DP}_{2}\right.$ den Fritz $]{ }_{\mathrm{DP}_{3}} \mathrm{t}_{1}$ für Bücher $] \mathrm{t}_{2}$ beeindruckt ? what have PRT the Fritz

c. Was ${ }_{1}$ haben $\left[\mathrm{DP}_{2}\right.$ den Fritz $]$ denn $\left[\mathrm{DP}_{3} \mathrm{t}_{1}\right.$ für Bücher $] \mathrm{t}_{2}$ beeindruckt ? what have the Fritz ${ }_{a c c}$ PRT for books ${ }_{n o m}$ impressed

d. * ${ }_{\mathrm{PP}_{1}}$ Über wen ] hat wohl $\left[\mathrm{DP}_{3}\right.$ ein Buch $\left.\mathrm{t}_{1}\right]\left[\mathrm{DP}_{2}\right.$ den Fritz $]$ beeindruckt ? about whom has PRT a book nom $_{\text {the }}$ Fritz $a c c$ impressed

e. [ $\mathrm{PP}_{1}$ Über wen ] hat wohl $\left[\mathrm{DP}_{2}\right.$ den Fritz $]\left[\mathrm{DP}_{3}\right.$ ein Buch $\left.\mathrm{t}_{1}\right] \mathrm{t}_{2}$ beeindruckt? about whom has PRT the Fritz

f. [ $\mathrm{PP}_{1}$ Über wen ] hat $\left[\mathrm{DP}_{2}\right.$ den Fritz ] wohl $\left[\mathrm{DP}_{3}\right.$ ein Buch $\left.\mathrm{t}_{1}\right] \mathrm{t}_{2}$ beeindruckt ? about whom has the Fritz ${ }_{a c c}$ PRT a book ${ }_{\text {nom }}$ impressed

Consider finally what happens when these kinds of particles are added in a position to the right of the subject DP. On the one hand, it does not come as a surprise that judgements for (49-ac) stay as they are for the corresponding examples in (48-ad) (the subject DP is an island to begin with, independently of a freezing effect, and there is no melting configuration because the object has not passed the subject). On the other hand, an order with the particle following both the

\footnotetext{
41 The data reported here are based on an informal survey among eight native speaker linguists. The judgements were nearly unanimous: Adding a particle in front of the subject DP does not improve grammaticality. Diesing $(1992,32)$ has contradictory judgements for data of the type in (48-a) and (48-d). I do not follow her judgements here; but it might still be worth noting that if one were to adopt Diesing's (1992) view, this would in fact follow in the present approach as a melting effect under the assumption that particles like denn and wohl enter the syntactic derivation as a result of designated structure-building features on $\mathrm{v}$, rather than by some other (adjunction-like) operation, as assumed here.
} 
subject (from which extraction takes place) and the object also leads to ungrammaticality; see (49-bd). This follows as a freezing effect: Given that the particles demarcate the left edge of vP after external Merge, movement of the subject must be involved here (to an outer specifier of $\mathrm{v}$, since optional raising to SpecT would exclude subsequent object scrambling to a position in front of it); this creates a freezing effect which cannot be undone by object fronting (given the assumptions laid out in the previous section).

(49) a. * $\mathrm{Was}_{1}$ haben $\left[\mathrm{DP}_{3} \mathrm{t}_{1}\right.$ für Bücher $]$ denn $\mathrm{t}_{3}\left[\mathrm{DP}_{2}\right.$ den Fritz $]$ beeindruckt ? what have for books $s_{n o m}$ PRT the Fritz acc $_{\text {impressed }}$

b. *Was ${ }_{1}$ haben $\left[\mathrm{DP}_{2}\right.$ den Fritz ] $\left[\mathrm{DP}_{3} \mathrm{t}_{1}\right.$ für Bücher ] denn $\mathrm{t}_{3} \mathrm{t}_{2}$ beeindruckt ? what have the Fritz focc $_{\text {fooks }}$ fom PRT impressed

c. $*\left[\mathrm{PP}_{1}\right.$ Über wen $]$ hat $\left[\mathrm{DP}_{3}\right.$ ein Buch $\left.\mathrm{t}_{1}\right]$ wohl $\mathrm{t}_{3}\left[{ }_{\mathrm{DP}_{2}}\right.$ den Fritz $]$ beeindruckt ? about whom has a book $_{n o m}$ PRT the Fritz $a c c$ impressed

d. * $\left[\mathrm{PP}_{1}\right.$ Über wen ] hat $\left[\mathrm{DP}_{2}\right.$ den Fritz $]\left[\mathrm{DP}_{3}\right.$ ein Buch $\left.\mathrm{t}_{1}\right]$ wohl $\mathrm{t}_{3} \mathrm{t}_{2}$ beeindruckt ? about whom has the Fritz $a c c$ a book nom $_{\text {PRT impressed }}$

To end this section, let me turn to a derivation that may at first sight seem problematic for the present approach because it looks as though it might indicate a loophole offering melting derivations for non-melting (i.e., ungrammatical) constructions. Consider the following, alternative derivation of a non-melting example like (36-a):

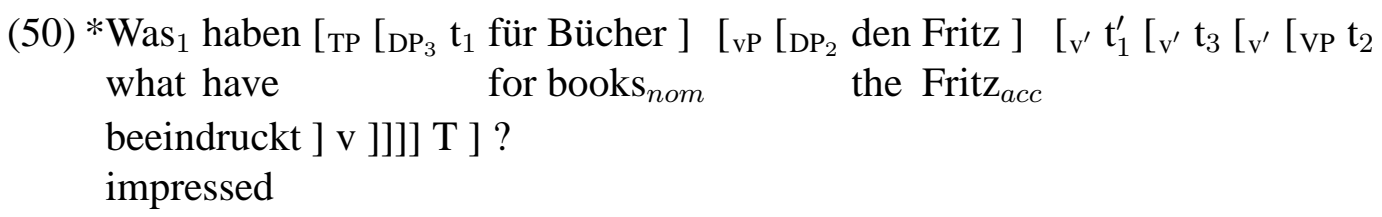

Here, the object $\mathrm{DP}_{2}$ is scrambled to an outer specifier of $\mathrm{vP}$, in front of the subject's base position. Before the object undergoes scrambling, the subject would therefore be predicted to be transparent for extraction: An edge feature can be assigned to $\mathrm{v}$ because the phase head is still active at this point, bearing the $[\bullet \Sigma \bullet]$ feature for local object scrambling; and the wh-phrase was may thus move to an outer specifier before the object is scrambled. From this position, it may then move to SpecC in accordance with the PIC (via SpecT, a further intermediate step that is not indicated in (50)). All this is as in genuine melting examples like (36-b). However, there is a crucial difference between (50) and (36-b): In the latter example, the subject DP stays in situ; but in the former, it undergoes optional raising to SpecT (triggered by an EPP feature that can optionally be present on T).

Given the assumptions made so far, there is nothing wrong with the derivation in (50), but it must of course be excluded in some way. Various possible solutions suggest themselves; I will briefly sketch two. First, note that (50) instantiates a type of Duke-of-York derivation (see Pullum (1979)) based on the interaction of optional movements that is well known as a potential 
problem for theories of movement, independently of the issues that are presently under consideration. The order $\mathrm{A} \sim \mathrm{B}$ is first changed into the order $\mathrm{B} \sim \mathrm{A}$, which is subsequently changed into an order $\mathrm{A} \sim \mathrm{B}$ again, with no interaction with other material $(\mathrm{C})$ involved. As argued by Ross (1967) and Haider (1993) (among many others), such cases of globally string-vacuous optional movement, which reproduces the very same order that was present initially at the end of the derivation, need to be blocked in any theory that envisages optional movement; otherwise sentences could have infinite numbers of legitimate derivations. ${ }^{42}$ Duke-of-York derivations resulting in globally string-vacuous movement of the type in (50) could be prohibited by adopting an economy constraint on optional features in numerations: The insertion of optional features in numerations is blocked if these features do not have an effect on outcome. ${ }^{43}$

An alternative solution to the problem of excluding (50) would be to assume that subjects are in fact not part of the edge domain of $\mathrm{vP}$ in their base position; only a derived specifier would count as part of the edge (see Müller (2007)). Then, movement of the subject $\mathrm{DP}_{3}$ in (50) would have to proceed via a further specifier of $\mathrm{vP}$, and this would give rise to the dilemma for freezing derivations sketched in section $4-$ both the subject $\mathrm{DP}_{3}$ and the wh-element to be extracted from it then need to move to an outer specifier of $v$, triggered by $[\bullet \mathrm{D} \bullet]$ in one case,

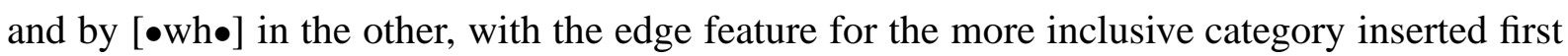
(and, as a consequence, insertion for the dominated category not available anymore). The two solutions differ slightly in their predictions, but both seem viable in principle. ${ }^{44}$

There may well be other derivations that may at first sight look like they provide loopholes for extraction, but it seems to me that there is no reason to assume that they cannot be excluded

\footnotetext{
42 Note that whereas globally string-vacuous movement would be excluded, this would not hold for locally stringvacuous movement, as it in fact had to be assumed to be legitimate above. Locally string-vacuous movement differs from globally string-vacuous movement in that it eventually (at the end of the derivation) leads to new orders of items.

${ }^{43}$ See Müller (1998) for such a constraint, which also derives various kinds of improper movement effects that were subsumed under the Principle of Unambiguous Binding (PUB) in Müller \& Sternefeld (1993).

44 An object DP may cross adverbial material (adjuncts) or particles but end up below the subject. As for adverbs, it could be assumed that they show up in a position c-commanded by $\mathrm{v}$ in this case, either in a VP specifier, or in a designated functional projection intervening between vP and VP - recall that the barrier status of adjuncts is derived if these items are last-merged specifiers of special functional projections (see Alexiadou (1997), Cinque (1999)). As for particles, which I have explicitly assumed to demarcate the vP edge (following standard practice), the order $\mathrm{DP}_{n o m} \sim \mathrm{DP}_{a c c} \sim \mathrm{PRT}$, which is possible as such, would have to be derived by movement. The subject DP remains a barrier in this construction:
}

(i) *Was ${ }_{1}$ haben $\left[\mathrm{DP}_{3} t_{1}\right.$ für Bücher $]\left[\mathrm{DP}_{2}\right.$ den Fritz $]$ denn $t_{3} t_{2}$ beeindruckt? what have for books nom $_{\text {fitz }}$ the PRT impressed 
a similar way, by invoking independently motivated constraints. ${ }^{45}$ In general, then, I take the melting effect to be well established. Most of the examples I have discussed involve the vP domain, and this is certainly not accidental. The $\mathrm{vP}$ domain has exactly the properties that are favourable to the occurrence of melting: It is as a domain that hosts an externally merged specifier (the external argument), as well as possible further internally merged specifiers (scrambled items that stay in this position for the rest of the derivation). The VP domain is similar in this respect in double object contexts, and a melting effect can be observed here, too. Other domains lacking this dual role (e.g., CP and TP, which only have derived specifiers, except perhaps for items like expletives that extraction cannot take place from for obvious reasons) are therefore not expected to show melting effects. Still, it is likely that melting effects can be found in other domains as well (e.g., NP and PP); but I will have to leave that for future research.

\section{Outlook and Conclusion}

\subsection{Outlook}

It has sometimes been claimed, for certain movement types or certain languages, that subjects are not necessarily barriers for extraction, or that, more generally, the CED does not hold; see Haider (1983; 1993) on German, Frantz (1980) on Blackfoot, Bickel (2004) on Belhare, Lasnik \& Saito (1992), Takahashi (1994), Rackowski \& Richards (2005) on Japanese (for null operator movement), and Stepanov (2007) on Navajo, Turkish, Palauan, Hungarian, and Russian. ${ }^{46}$ As

Here, the second analysis (in terms of a narrower concept of edge) might offer a somewhat simpler account than the first analysis (that relies on a ban on globally string-vacuous movement): Movement in (i) is not globally string-vacuous, but it instantiates a freezing effect if $\mathrm{DP}_{3}$ obligatorily moves to Specv.

45 To name just one example: As observed by Winnie Lechner (p.c.), a melting effect fails to show up in cases like (i-a), where v could be assumed to be equipped with two $[\bullet \Sigma \bullet]$ features, and both PPs undergo scrambling to Specv, with $\mathrm{PP}_{1}$ being extracted out of $\mathrm{PP}_{2}$ after the latter has undergone scrambling (and $\mathrm{v}$ still active at this point, due to the remaining $[\bullet \Sigma \bullet]$ feature).

(i) a. *dass sie $\quad\left[\mathrm{vP}_{\mathrm{vP}}\left[\mathrm{PP}_{1}\right.\right.$ über Bakunin $]\left[\mathrm{v}_{\mathrm{v}^{\prime}}\left[\mathrm{PP}_{2}\right.\right.$ von einem Vortrag $\left.\mathrm{t}_{1}\right]\left[\mathrm{v}_{\mathrm{v}^{\prime}}\left[\mathrm{DP}_{3}\right.\right.$ eine Aufzeichnung $\left.\mathrm{t}_{2}\right]$ that she nom $_{\text {about Bakunin of a talk a recording }}$ acc machte ]]] made

b. *dass sie $\quad\left[\mathrm{vP}\left[\mathrm{PP}_{1}\right.\right.$ über Bakunin $]\left[\mathrm{v}^{\prime}\left[\mathrm{DP}_{3}\right.\right.$ eine Aufzeichnung $\left[\mathrm{PP}_{2}\right.$ von einem Vortrag $\left.\left.\mathrm{t}_{1}\right]\right]$ machte $\left.]\right]$ that she $_{n o m}$ about Bakunin a recording $a c c$ of a talk made

However, notwithstanding the fact that extraction of a PP from a PP is ungrammatical for independent reasons in German (see (i-b), with $\mathrm{PP}_{2}$ in situ), (i-a) instantiates scrambling from a scrambled item, which is a configuration of just the type shown to be generally impossible in section 4 above.

46 Rackowski \& Richards $(2005,585)$ assume that CED effects with subjects can be avoided if a language can a establish an Agree relation between v and a specifier, in violation of the c-command requirement on Agree relations 
noted above, at least for German, it seems to me that many of the putative counter-examples to the generalization that subjects in Specv are islands can be rejected by showing that they either involve VP-internal arguments or no extraction at all (or melting); and it does not strike me as unlikely that similar explanations can be given for many apparent counter-examples in other languages. However, at present I take it to be an open question whether such a way out is available for all constructions, and all languages where apparent exceptions from the CED have been observed.

One case that is instructive in this context is the behaviour of expletive constructions in English. In English expletive there constructions, the associate DP is not inherently a barrier; see (51-a). In contrast, DP is a barrier for extraction in locative inversion constructions, as in (51-b) (see Moro (1997)).

(51) a. Which wall ${ }_{1}$ do you think there ${ }_{3}$ was $\left[\mathrm{vP}_{3}\left[\mathrm{v}^{\prime} \mathrm{v}\left[\mathrm{DP}_{2}\right.\right.\right.$ a picture of $\left.\left.\left.\mathrm{t}_{1}\right]\right]\right]$ ?

b. $* \mathrm{Who}_{1}$ do you think $\left[\mathrm{PP}_{3}\right.$ on this wall $]$ hung $\left[\mathrm{DP}_{2}\right.$ a picture of $\left.\mathrm{t}_{1}\right] \mathrm{t}_{3}$ ?

Does the wellformedness of (51-a) raise a problem for the view that last-merged specifiers of $\mathrm{vP}$ are islands? Given the present system of assumptions, the contrast in (51) would seem to suggest that $\mathrm{DP}_{2}$ in (51-b) is last-merged in its projection whereas $\mathrm{DP}_{2}$ in (51-a) is not. I take it to be uncontroversial that $\mathrm{DP}_{2}$ is indeed last-merged in its projection (51-b), with $\mathrm{PP}_{3}$ initially occupying a lower position and then undergoing raising to an outer specifier position (perhaps SpecT). As for (51-a), the absence of a CED effect follows immediately if one assumes that there is a subject and $\mathrm{DP}_{2}$ is its predicate (see Williams $(1994 ; 2006)$ ), with the two items merged in the same projection (vP), as argued in Hazout (2004) and Hartmann (2005). If so, $\mathrm{DP}_{2}$ in (51-a) is in fact not last-merged in its projection because there is merged later, in the same projection, as indicated (subsequently, there undergoes raising to $\mathrm{SpecT}$ ). Therefore, $\mathrm{DP}_{2}$ does not have to be an island for extraction.

Another case that might shed some light on this issue is that of a German expletive pronoun es optionally accompanying a finite subject clause from which extraction has taken place. Fanselow \& Mahajan (2000) claim that (52-a) (extraction in the presence of $e s$ ) is just as good as (52-b) (extraction from a subject clause without es being present); interestingly, for some speakers, the presence of es actually improves the example. (That said, for what is perhaps the majority of speakers, both examples are equally ungrammatical, as one would expect under the approach developed above; also see Stechow (2000).)

assumed in Chomsky $(2001 ; 2008)$ and much related work. 
a. \#Wen 1 ärgert es dich [CP dass sie $t_{1}$ liebt $]$ ? whom $_{a c c}$ annoys it you acc $_{\text {an }}$ that she ${ }_{n o m}$ loves

b. \#Wen $n_{1}$ ärgert dich [CP dass sie $\mathrm{t}_{1}$ liebt ] ? whom $_{a c c}$ annoys you acc $_{\text {and }}$ that shom $_{\text {nov }}$

Suppose, at least for the sake of illustration, that the amelioration effect triggered by the presence of es is real. In the present system, this could then be interpreted as a kind of "pseudomelting" effect, similar to the situation in there-constructions: If one assumes (i) that the (phrase headed by the) expletive does not stand in a dominance relation with the subject clause (contra Ross (1967) and much later work), and (ii) that the expletive is merged after the finite subject clause, but within the same projection, then some item in the left edge of the subject clause will be able to undergo edge-feature driven movement to an outer vP specifier (while the subject clause is still in situ), and a CED effect can be avoided. Such an analysis in terms of [•expl•] features (which presumably would by definition have to be ordered between standard subcategorization features and movement-inducing features in features stacks of lexical items) might then possibly be extended to cases like (52-b) - in other words, zero expletives might underlie an absence of CED effects. ${ }^{47}$ Still, as remarked above, it is far from clear whether either one or both of the examples in (52) should indeed be categorized as grammatical in the first place (and if they are not, giving up assumption (i) or assumption (ii) will suffice to maintain the CED effect).

The problems just noted notwithstanding, it is worth pointing out that this approach might also contribute to a solution of a well-known problem that shows up with many theories of locality in a domain where judgements are much less controversial, viz., wh-extraction (or relativzation, or topicalization) from infinitives in German: In contrast to finite clauses, subject (and object) infinitives are transparent for extraction in German (cf. Haider (1983; 1993), Sternefeld (1985), and Grewendorf (1989)). A pair of examples that shows this effect is (53-bc), with the subject infinitive in the pre-subject (base) and in an extraposed position. In (53-a), the subject infinitive is accompanied by an expletive $e s$, and extraction is also possible. ${ }^{48}$

(53) a. Was $\mathrm{Wat}_{1}$ hat es sich nicht gehört [CP $\mathrm{t}_{1}^{\prime} \mathrm{PRO} \mathrm{t}_{1} \mathrm{zu}$ beanstanden ] ? what $_{a c c}$ has it not been proper to object to

\footnotetext{
47 The analysis sketched here presupposes that CP extraposition from a Specv (or, for that matter, VP-internal complement) position does not create an island, as an instance of freezing. A freezing effect can be avoided with extraction from a CP if CP extraposition targets a high position, making it an instance of remnant movement; see Müller (1998).

${ }^{48}$ Note that (53-a) must involve extraposition, as is typical in the presence of expletives that accompany clauses.
} 
b. Was hat $_{1} \mathrm{CP}_{1}^{\prime}$ PRO $\mathrm{t}_{1} \mathrm{zu}$ beanstanden $]$ sich nicht gehört? what $_{a c c}$ has to object to not been proper

c. $\mathrm{Was}_{1}$ hat sich nicht gehört [CP $\mathrm{t}_{1}^{\prime} \mathrm{PRO} \mathrm{t}_{1} \mathrm{zu}$ beanstanden ] ? what ${ }_{a c c}$ has not been proper to object to

Assuming that evidence for a zero expletive alternating with es can be found in this case, the transparency of all kinds of subject infinitives in German could be treated as another instance of a pseudo-melting effect.

Needless to say, all these remarks are highly speculative, and the late-merged items creating pseudo-melting effects postulated by these analyses would eventually have to be substantiated by independent evidence. However, the main purpose of this subsection is not to justify actual analyses, but rather to show a direction in which one might profitably look upon encountering exceptions to the CED with external arguments in Specv that are transparent for extraction (or related configurations), in a given language: In those cases, it might well be that there is a (possibly non-overt) item that is merged later, in the same projection, which thereby permits the insertion of an edge feature for some item in the specifier of an otherwise opaque XP, thereby creating a pseudo-melting effect. ${ }^{49}$

\subsection{Conclusion}

I have shown that the version of the Condition on Extraction Domain (CED) in (4) (according to which some item is a barrier if the operation that has merged it in a phrase is the final operation taking place in that phrase) follows as a theorem in a derivational theory of syntax that incorporates the Phase Impenetrability Condition (PIC) and the four assumptions in (54).

(54) a. All syntactic operations are driven by features of lexical items.

b. These features are ordered on lexical items.

c. All phrases are phases.

d. Edge features that trigger intermediate movement steps can be added only as long as the phase head is still active.

The question arises to what extent these four main assumptions underlying the present analysis are crucial; after all, it might be that abandoning one or more of these assumptions does not necessarily imply that no (relevant) version of the CED can be derived. In fact, closer inspection reveals that the four assumptions are not equally important.

\footnotetext{
49 This reasoning is comparable to Bittner \& Hale's (1996) treatment of accusative case assignment in terms of abstract pseudo-coarguments.
} 
Consider first assumption (54-c). As argued in section 2.3, I think there is solid independent evidence (both empirical and conceptual) for assuming that all phrases are phases, in the sense of the PIC. Still, if one assumes that there are fewer phases, this may diminish some of the empirical impact of the CED then derivable, but it in no way undermines the theorem status of the CED as such. For concreteness, suppose that only vP and CP are phases; then the (lastmerged) specifiers of vP and $\mathrm{CP}$ are derived as islands. If DP is also a phase, then DP specifiers come out as islands, too; and so on. This arguably does not cover all the observable CED effects, but it covers most of the effects discussed in the present paper, and thus represents an interesting result. ${ }^{50}$

Turning next to assumption (54-a), I would again like to contend that whereas adopting it is well motivated (given an incremental, minimalist approach to structure-building where the Inclusiveness Condition ensures that all operations are driven by the properties of lexical items); but it can easily be replaced with alternative assumptions without threatening to undermine the overall approach. The main task of assumption (54-a) is to make it possible to decide, at any given step of the derivation, whether a phase head is still active, or has become inert. In the present approach, the (in-)activity of a phase head can be determined by inspecting whether it has any (probe or structure-building) features left to discharge; but if the (in-)activity of a phase head can be determined in some other way (e.g., by carrying out semantic interpretation cyclically), then this will also be sufficient for deriving CED effects from the PIC.

Similar considerations apply in the case of assumption (54-b). The hypothesis that operation-inducing features on a lexical item are ordered in stacks can be taken to be independently motivated, and it permits a simple account of the last-in/first-out property of edge feature insertion, but replacing it with an alternative assumption that does not rely on feature hierarchies would leave most of the reasonings above intact (potentially giving rise to analyses of the type discussed in footnote 40). ${ }^{51}$ Again, what is crucial is that there is some notion of a phase head becoming inert at some stage of the derivation.

Let me finally turn to assumption (54-d): Edge features that trigger intermediate movement steps can be added only as long as the phase head is still active. Replacing after with before in the Edge Feature Condition (as documented in the different definitions in (3) and (9)) forms

\footnotetext{
${ }^{50}$ Since phases thus help to account for CED effects, under any definition (narrow or broad), the present paper can be viewed as an argument in support of the general concept of a phase. It certainly calls into question the claim that "locality doesn't offer any argument for phases" (cf. Boeckx \& Grohmann $(2007,214)$ ).

51 Of course, dispensing with assumption (54-a) implies dispensing with assumption (54-b) as well, whereas the opposite does not hold.
} 
the gist of the present paper. At least at first sight, this would seem to be the sole indispensable part of the derivation of CED effects from the PIC. However, even here we can distinguish between the underlying idea and its technical implementation, and replace the latter within alternative systems of movement and structure-building. What is needed is some way of classifying intermediate movement steps as costly; some operation $\zeta$ is required to effect them, and $\zeta$ 's application is restricted to contexts in which the phase head is still active. In the present approach, $\zeta$ is the insertion of an edge feature; but $\zeta$ could in principle be any other means triggering intermediate movement steps. ${ }^{52}$ This is then the irreducible core of the present proposal: Operation $\zeta$ (however it is defined) is responsible for inducing movement to (intermediate) phase edges, and $\zeta$ can only apply at any given step of the derivation if the phase head providing the phase edge qualifies as still "active" (however this is defined). Under this assumption, the CED effects follow from the PIC, in line with Chomsky's informal proposal that "what yields the subject-island effect, it appears, is search that goes to deeply into a phase already passed" (see Chomsky $(2008,154))$.

Last but not least, I would like to emphasize a general point. Deriving CED effects from the PIC in the way laid out in this paper is only possible in a derivational approach to syntax that recognizes before and after as basic theoretical concepts, and in which there is a total order of all operations in a derivation (and thus no room for operations applying simultaneously in a single phrase marker). Therefore, to the extent that the account can be characterized as successful, it provides an argument for a strictly derivational organization of grammar.

\footnotetext{
${ }^{52}$ Here are two possible options that do without edge features (others are conceivable): First, on the basis of the non-feature driven approach developed in Heck \& Müller (2000; 2003) (see footnote 4), $\zeta$ could be assumed to be movement to an intermediate position that violates Last Resort in order to satisfy Phase Balance; and the assumption replacing the EFC in (9) might be that a phase automatically counts as balanced if its phase head is inert. An inert phase head would thus make a Last Resort violation incurred by an intermediate movement step fatal, thereby yielding a PIC violation on the subsequent cycle with last-merged specifiers. Second, against the background of Chomsky (1993), $\zeta$ may be understood as movement to intermediate positions that violates the Fewest Steps condition but is required for convergence of the derivation; the assumption replacing the EFC in (9) might then be that convergence holds by definition if the head of the landing site is not syntactically active anymore. This would imply the selection of a derivation that minimizes the number of movement steps in CED contexts, which violates the PIC.
} 


\section{Bibliography}

Abels, Klaus (2003): Successive Cyclicity, Anti-Locality, and Adposition Stranding. PhD thesis, University of Connecticut, Storrs, Connecticut.

Abels, Klaus (2006): Towards a Restrictive Theory of (Remnant) Movement: Improper Movement, Remnant Movement, and a Linear Asymmetry. Ms., University of Troms $\varnothing$.

Abels, Klaus \& Kristine Bentzen (2008): Is There Any Evidence for Punctuated Paths?. Ms., University College London and University of Troms $\varnothing$.

Abney, Steven (1987): The English Noun Phrase in Its Sentential Aspect. PhD thesis, MIT, Cambridge, Mass.

Adger, David (2003): Core Syntax. Oxford University Press, Oxford, New York.

Agbayani, Brian (1998): Feature Attraction and Category Movement. PhD thesis, UC Irvine.

Alexiadou, Artemis (1997): Adverb Placement. Benjamins, Amsterdam.

Alexiadou, Artemis, Liliane Haegeman \& Melita Stavrou (2007): Noun Phrase in the Generative Perspective. De Gruyter, Berlin, New York.

Bach, Emmon \& George Horn (1976): Remarks on 'Conditions on Transformations', Linguistic Inquiry pp. 265-299.

Baker, Mark (1988): Incorporation. A Theory of Grammatical Function Changing. University of Chicago Press, Chicago.

Barbiers, Sjef (2002): Remnant Stranding and the Theory of Movement. In: Dimensions of Movement. Benjamins, Amsterdam, pp. 47-67.

Bayer, Josef \& Jaklin Kornfilt (1994): Against Scrambling as an Instance of Move Alpha. In: N. Corver \& H. van Riemsdijk, eds., Studies on Scrambling. Mouton de Gruyter, Berlin, pp. 17-60.

Bech, Gunnar (1955/1957): Studien über das deutsche Verbum Infinitum. Niemeyer, Tübingen. Reprint 1983.

Beck, Sigrid (1997): Wh-Constructions and Transparent Logical Form. PhD thesis, Universität Tübingen.

Bhatt, Rajesh (2005): Long Distance Agreement in Hindi-Urdu, Natural Language and Linguistic Theory 23, 757-807.

Bickel, Balthasar (2004): Constraining Focus and Extraction Domains. Ms., Universität Leipzig. (Talk presented at Syntax of the World's Languages 1).

Bierwisch, Manfred (1988): On the Grammar of Local Prepositions. In: M. Bierwisch, W. Motsch \& I. Zimmermann, eds., Syntax, Semantik und Lexikon. Rudolf Růžička zum 65. Geburtstag. Akademie-Verlag, Berlin, pp. 1-65.

Bittner, Maria \& Ken Hale (1996): The Structural Determination of Case and Agreement, Linguistic Inquiry pp. 1-68.

Bobaljik, Jonathan \& Susi Wurmbrand (2003): Relativized Phases. Ms., University of Connecticut, Storrs.

Boeckx, Cedric (2003): Islands and Chains. Resumption as Stranding. Benjamins, Amsterdam.

Boeckx, Cedric (2004): Long-distance Agreement in Hindi: Some Theoretical Implications, Studia Linguistica 58, 23-36.

Boeckx, Cedric (2008): Understanding Minimalist Syntax. Blackwell, Oxford.

Boeckx, Cedric \& Kleanthes K. Grohmann (2007): Putting Phases in Perspective, Syntax pp. 204-222.

Borer, Hagit (2004): Structuring Sense. An Exo-Skeletal Trilogy. Vols 1 and 2. Oxford University Press, Oxford.

Bošković, Željko (2002): A-Movement and the EPP, Syntax 5, 167-218.

Bošković, Željko (2007): Agree, Phases, and Intervention Effects, Linguistic Analysis 33, 5496.

Broekhuis, Hans (2005): Extraction from Subjects: Some Remarks on Chomsky's 'On Phases'. In: H. Broekhuis, N. Corver, R. Huybregts, U. Kleinherz \& J. Koster, eds., Organizing Gram- 
mar. Studies in Honor of Henk van Riemsdijk. Mouton de Gruyter.

Browning, Maragaret (1991): Bounding Conditions on Representations, Linguistic Inquiry 22, 541-562.

Cattell, Ray (1976): Constraints on Movement Rules, Language 52, 18-50.

Chomsky, Noam (1973): Conditions on Transformations. In: S. Anderson \& P. Kiparsky, eds., A Festschrift for Morris Halle. Academic Press, New York, pp. 232-286.

Chomsky, Noam (1986): Barriers. MIT Press, Cambridge, Mass.

Chomsky, Noam (1993): A Minimalist Program for Syntactic Theory. In: K. Hale \& S. J.

Keyser, eds., The View from Building 20. MIT Press, Cambridge, Mass., pp. 1-52.

Chomsky, Noam (1995): The Minimalist Program. MIT Press, Cambridge, Mass.

Chomsky, Noam (2000): Minimalist Inquiries: The Framework. In: R. Martin, D. Michaels \&

J. Uriagereka, eds., Step by Step. MIT Press, Cambridge, Mass., pp. 89-155.

Chomsky, Noam (2001): Derivation by Phase. In: M. Kenstowicz, ed., Ken Hale. A Life in Language. MIT Press, Cambridge, Mass., pp. 1-52.

Chomsky, Noam (2005): Three Factors in Language Design, Linguistic Inquiry 36, 1-22.

Chomsky, Noam (2007): Approaching UG from Below. In: U. Sauerland \& H.-M. Gärtner, eds., Interfaces + Recursion $=$ Language . Mouton de Gruyter, Berlin, pp. 1-31.

Chomsky, Noam (2008): On Phases. In: R. Freidin, C. Otero \& M. L. Zubizarreta, eds., Foundational Issues in Linguistic Theory. MIT Press, Cambridge, Mass., pp. 133-166.

Chung, Sandra (1994): Wh-Agreement and 'Referentiality' in Chamorro, Linguistic Inquiry $25,1-44$.

Cinque, Guglielmo (1990): Types of A-bar Dependencies. MIT Press, Cambridge, Mass.

Cinque, Guglielmo (1999): Adverbs and Functional Heads. Oxford University Press, Oxford.

Clements, George, James McCloskey, Joan Maling \& Annie Zaenen (1983): String-Vacuous Rule Application, Linguistic Inquiry 14, 1-17.

Collins, Chris (1993): Topics in Ewe Syntax. PhD thesis, MIT, Cambridge, Mass.

Collins, Chris (1994): Economy of Derivation and the Generalized Proper Binding Condition, Linguistic Inquiry 25, 45-61.

Collins, Chris (2003): Eliminating Labels. In: S. D. Epstein \& T. D. Seely, eds., Derivation and Explanation in the Minimalist Program. Blackwell, Oxford, pp. 42-64.

Davies, William \& Stanley Dubinsky (2003): On Extraction from NPs, Natural Language and Linguistic Theory 21, 1-37.

den Besten, Hans \& Gert Webelhuth (1990): Stranding. In: G. Grewendorf \& W. Sternefeld, eds., Scrambling and Barriers. Benjamins, Amsterdam, pp. 77-92.

den Dikken, Marcel (2007): Phase Extension: Contours of a Theory of the Role of Head Movement in Phrasal Extraction, Theoretical Linguistics 33, 1-41.

den Dikken, Marcel (2008): Small Clauses, Phases, and Phase Extension - The Case of Scope and Object Shift. Ms.,CUNY Graduate Center. (Talk at Glow 2008, Newcastle).

Diesing, Molly (1992): Indefinites. MIT Press, Cambridge, Mass.

Epstein, Samuel David \& T. Daniel Seely (2002): Rule Applications as Cycles in a Level-Free Syntax. In: S. D. Epstein \& T. D. Seely, eds., Derivation and Explanation in the Minimalist Program. Blackwell, Oxford, pp. 65-89.

Fanselow, Gisbert (1987): Konfigurationalität. Narr, Tübingen.

Fanselow, Gisbert (2001a): Features, Theta-Roles, and Free Constituent Order, Linguistic Inquiry 32, 405-436.

Fanselow, Gisbert (2001b): When Formal Features Need Company. In: C. Féry \& W. Sternefeld, eds., Audiatur Vox Sapientiae. A Festschrift for Arnim von Stechow. Akademie-Verlag, Berlin, pp. 131-152.

Fanselow, Gisbert \& Anoop Mahajan (2000): Towards a Minimalist Theory of Wh-Expletives, Wh-Copying, and Successive Cyclicity. In: U. Lutz, G. Müller \& A. von Stechow, eds., Wh-Scope Marking. Benjamins, Amsterdam, pp. 195-230. 
Fanselow, Gisbert \& Damir Ćavar (2001): Remarks on the Economy of Pronunciation. In: G. Müller \& W. Sternefeld, eds., Competition in Syntax. Mouton de Gruyter, Berlin, pp. 107150.

Fanselow, Gisbert \& Denisa Lenertová (2007): Movement to Spec,CP and Linearization. Ms., Universität Potsdam \& Universität Leipzig.

Fischer, Silke (2004): Towards an Optimal Theory of Reflexivization. PhD thesis, Universität Tübingen.

Fox, Danny (2000): Economy and Semantic Interpretation. MIT Press, Cambridge, Mass.

Frantz, Donald (1980): Ascensions to Subject in Blackfoot. In: Proceedings of the 6th Annual Meeting of the Berkeley Linguistics Society. BLS, Berkeley, University of California, pp. 293-299.

Gallego, Ángel (2007): Phase Theory and Parametric Variation. PhD thesis, Universitat Autónoma de Barcelona, Barcelona.

Gallego, Ángel \& Juan Uriagereka (2006): Sub-Extraction from Subjects. Ms., Universitat Autónoma de Barcelona.

Gazdar, Gerald (1981): Unbounded Dependencies and Coordinate Structure, Linguistic Inquiry $12,155-184$.

Gazdar, Gerald, Ewan Klein, Geoffrey Pullum \& Ivan Sag (1985): Generalized Phrase Structure Grammar. Blackwell, Oxford.

Georgi, Doreen \& Gereon Müller (2008): Noun Phrase Structure by Reprojection. Ms., Universität Leipzig. To appear in Syntax.

Grewendorf, Günther (1989): Ergativity in German. Foris, Dordrecht.

Grewendorf, Günther (2003): Improper Remnant Movement, Gengo Kenkyo: The Journal of the Linguistic Society of Japan 123, 47-94.

Grewendorf, Günther (2004): Die linke Bewegung von Restkategorien. Ms., Universität Frankfurt/Main.

Grewendorf, Günther \& Joachim Sabel (1994): Long Scrambling and Incorporation, Linguistic Inquiry 25, 263-308.

Grewendorf, Günther \& Joachim Sabel (1999): Scrambling in German and Japanese, Natural Language and Linguistic Theory 17, 1-65.

Grohmann, Kleanthes K. (2000): Prolific Peripheries: A Radical View From the Left. PhD thesis, University of Maryland.

Grohmann, Kleanthes K. (2003): Successive Cyclicity under (Anti-)Local Considerations, Syn$\operatorname{tax} 6,260-312$.

Haider, Hubert (1983): Connectedness Effects in German, Groninger Arbeiten zur Germanistischen Linguistik 23, 82-119.

Haider, Hubert (1988): Theta-Tracking Systems - Evidence from German. In: L. Marácz \& P. Muysken, eds., Configurationality. Foris, Dordrecht, pp. 185-206.

Haider, Hubert (1993): Deutsche Syntax - generativ. Narr, Tübingen.

Haider, Hubert (2000): Branching and Discharge. In: P. Coopmans, M. Everaert \& J. Grimshaw, eds., Lexical Specification and Insertion. Benjamins, Amsterdam, pp. 135-164.

Haider, Hubert (2006): Zufall und Notwendigkeit bei der germanischen VO/OV-Spaltung. Ms., Universität Salzburg.

Hale, Ken \& Samuel Jay Keyser (2002): Prolegomenon to a Theory of Argument Structure. MIT Press, Cambridge, Mass.

Harley, Heidi (1995): Subjects, Events, and Licensing. PhD thesis, MIT.

Hartmann, Jutta (2005): Wh-Movement and the Small Clause Analyses of the English 'There'Construction, Leiden Papers in Linguistics 2.3, 93-106.

Hazout, Ilan (2004): The Syntax of Existential Constructions, Linguistic Inquiry 35, 393-430.

Heck, Fabian (2004): A Theory of Pied Piping. PhD thesis, Universität Tübingen.

Heck, Fabian \& Gereon Müller (2000): Successive Cyclicity, Long-Distance Superiority, and 
Local Optimization. In: R. Billerey \& B. D. Lillehaugen, eds., Proceedings of WCCFL. Vol. 19, Cascadilla Press, Somerville, MA, pp. 218-231.

Heck, Fabian \& Gereon Müller (2003): Derivational Optimization of Wh-Movement, Linguistic Analysis 33, 97-148.

Heck, Fabian \& Gereon Müller (2007): Extremely Local Optimization. Proceedings of WECOL 2006. California State University, Fresno.

Heck, Fabian \& Malte Zimmermann (2004): DPs as Phases. Ms., Universität Leipzig and HU Berlin.

Heck, Fabian, Gereon Müller \& Jochen Trommer (2007): A Phase-Based Approach to Scandinavian Definiteness Marking. Ms., Universität Leipzig. To appear in Proceedings of WCCFL 2007, Berkeley.

Heim, Irene \& Angelika Kratzer (1998): Semantics in Generative Grammar. Blackwell, Oxford.

Huang, Cheng-Teh James (1982): Logical Relations in Chinese and the Theory of Grammar. PhD thesis, MIT, Cambridge, Mass.

Johnson, Kyle (2003): Towards and Etiology of Adjunct Islands, Nordlyd 31(1), 187-215.

Jurka, Johannes (2008): Extraction out of Subjects in German. Ms., University of Maryland. (Talk at 36th Österreichische Linguistiktagung, Wien University, 2008).

Kitahara, Hisatsugu (1994): A Minimalist Analysis of Cross-Linguistically Variant CED Phenomena. In: Proceedings of NELS. Vol. 24, Amherst: GSLA, pp. 241-253.

Kitahara, Hisatsugu (1997): Elementary Operations and Optimal Derivations. MIT Press, Cambridge, Mass.

Kobele, Greg (2006): Generating Copies. PhD thesis, UCLA, Los Angeles.

Kobele, Greg (2009): Deriving Reconstruction Asymmetries. In: A. Alexiadou, T. Kiss \& G. Müller, eds., Local Modelling of Non-Local Dependencies in Syntax. Niemeyer, Tübingen.

Koster, Jan (1978): Locality Principles in Syntax. Foris, Dordrecht.

Koster, Jan (1986): The Relation Between Pro-Drop, Scrambling, and Verb Movements. Ms., Rijksuniversiteit Groningen.

Koster, Jan (1987): Domains and Dynasties. Foris, Dordrecht.

Koster, Jan (2000): Variable-Free Grammar. Ms., University of Groningen.

Kramer, Ruth (2007): The Amharic Definite Marker and the Syntax/PF Interface. Ms., University of California at Santa Cruz.

Kratzer, Angelika (1996): Severing the External Argument from its Verb. In: J. Rooryck \& L. Zaring, eds., Phrase Structure and the Lexicon. Kluwer, Dordrecht.

Kučerová, Ivona (2006): An Anti-Intervention Effect in Czech Splits: An Argument for Late Merge. In: R. Compton, M. Goledzinowska \& U. Savchenko, eds., Proceedings of FASL 15. Michigan Slavic Publications, Ann Arbor, pp. 161-179.

Lahne, Antje (2009): Where There is Fire There is Smoke. Local Modelling of SuccessiveCyclic Movement. PhD thesis, Universität Leipzig.

Larson, Richard (1988): On the Double Object Construction, Linguistic Inquiry 19, 335-391.

Lasnik, Howard \& Mamoru Saito (1992): Move $\alpha$. MIT Press, Cambridge, Mass.

Lechner, Winfried (2004): Extending and Reducing the MLC. In: A. Stepanov, G. Fanselow \& R. Vogel, eds., Minimality Effects in Syntax. Mouton de Gruyter, Berlin, pp. 205-240.

Legate, Julie Anne (2005): Phases and Cyclic Agreement, MITWPL 49, 147-156. Perspectives on Phases.

Leu, Thomas (2008): What for Internally, Syntax 11, 1-25.

Lewis, David (1972): General Semantics. In: D. Davidson \& G. Harman, eds., Semantics of Natural Language. Reidel, Dordrecht, pp. 169-218.

Manzini, Rita (1992): Locality. A Theory and Some of Its Empirical Consequences. MIT Press, Cambridge, Mass.

Marušič, Franc (2005): On Non-Simultaneous Phases. PhD thesis, Stony Brook University. 
Matushansky, Ora (2005): Going Through a Phase, MITWPL 49, 157-181. Perspectives on Phases.

McCloskey, James (1979): Transformational Syntax and Model Theoretic Semantics. A Case Study in Modern Irish. Reidel, Dordrecht.

McCloskey, James (2002): Resumptives, Successive Cyclicity, and the Locality of Operations. In: S. D. Epstein \& T. D. Seely, eds., Derivation and Explanation in the Minimalist Program. Blackwell, Oxford, pp. 184-226.

Moro, Andrea (1997): The Raising of Predicates: Predicative Noun Phrases and the Theory of Clause Structure. Cambridge University Press, Cambridge.

Müller, Gereon (1995): A-bar Syntax. Mouton/de Gruyter, Berlin.

Müller, Gereon (1998): Incomplete Category Fronting. Kluwer, Dordrecht.

Müller, Gereon (2004): Phrase Impenetrability and Wh-Intervention. In: A. Stepanov, G. Fanselow \& R. Vogel, eds., Minimality Effects in Syntax. Mouton de Gruyter, Berlin, pp. 289-325.

Müller, Gereon (2007): Towards a Relativized Concept of Cyclic Linearization. In: U. Sauerland \& H.-M. Gärtner, eds., Interfaces + Recursion = Language?. Mouton de Gruyter, Berlin, pp. 61-114.

Müller, Gereon (2008): Ergativity, Accusativity, and the Order of Merge and Agree. Universität Leipzig. To appear in Explorations of Phase Theory. Features, Arguments, and Interpretation at the Interfaces, ed. Kleanthes Grohmann. Berlin: Mouton de Gruyter.

Müller, Gereon (2009): Locality Constraints on Movement in a Phase-Based Approach to Syntax. Book ms., Universität Leipzig.

Müller, Gereon \& Wolfgang Sternefeld (1993): Improper Movement and Unambiguous Binding, Linguistic Inquiry 24, 461-507.

Neeleman, Ad \& Hans van de Koot (2007): A Local Encoding of Syntactic Dependencies and its Consequences for the Theory of Movement. Ms., University College London.

Nissenbaum, Jon (2000): Covert Movement and Parasitic Gaps. In: M. Hirotani, A. Coetzee, N. Hall \& J.-Y. Kim, eds., Proceedings of NELS 30. GLSA, Amherst, Mass, pp. 542-555.

Nunes, Jairo (2004): Linearization of Chains and Sideward Movement. MIT Press, Cambridge, Mass.

Nunes, Jairo \& Juan Uriagereka (2000): Cyclicity and Extraction Domains, Syntax 3, 20-43.

Pesetsky, David (1989): Language-Particular Processes and the Earliness Principle. Ms., MIT, Cambridge, Mass.

Pesetsky, David (2000): Phrasal Movement and Its Kin. MIT Press, Cambridge, Mass.

Pesetsky, David \& Esther Torrego (2006): Probes, Goals and Syntactic Categories. Ms., MIT. Lingbuzz/000321.

Polinsky, Maria \& Eric Potsdam (2001): Long-Distance Agreement and Topic in Tsez, Natural Language and Linguistic Theory 19, 583-646.

Pollard, Carl J. \& Ivan A. Sag (1994): Head-Driven Phrase Structure Grammar. University of Chicago Press, Chicago.

Postal, Paul (1972): Some Rules That Are Not Successive Cyclic, Linguistic Inquiry pp. 211222.

Pullum, Geoffrey (1979): Rule Interaction and the Organization of a Grammar. Garland, New York.

Rackowski, Andrea \& Norvin Richards (2005): Phase Edge and Extraction, Linguistic Inquiry 36, 565-599.

Ramchand, Gillian (2003): First Phase Syntax. Book ms., Oxford University.

Reis, Marga \& Inger Rosengren (1992): What do Wh-Imperatives Tell Us About WhMovement?, Natural Language and Linguistic Theory 10, 79-118.

Rezac, Milan (2004): Elements of Cyclic Syntax: Agree and Merge. PhD thesis, University of Toronto. 
Richards, Marc (2004): Object Shift and Scrambling in North and West Germanic: A Case Study in Symmetrical Syntax. PhD thesis, University of Cambridge, Cambridge, UK.

Richards, Marc (2007): Deriving the Edge: What's in a Phase?. Ms., Universität Leipzig.

Richards, Norvin (2001): Movement in Language. Oxford University Press, Oxford.

Riemsdijk, Henk van (1978): A Case Study in Syntactic Markedness: The Binding Nature of Prepositional Phrases. Foris, Dordrecht.

Rizzi, Luigi (2006): Criterial Freezing, EPP, and Asymmetries. Ms., Siena University.

Rizzi, Luigi (2007): On Some Properties of Criterial Freezing, CISCL Working Papers on Language and Cognition 1, 145-158.

Roberts, Ian \& Anna Roussou (2002): The Extended Projection Principle as a Condition for the Tense-Dependency. In: P. Svenonius, ed., Subjects, Expletives, and the EPP. Benjamins, Amsterdam.

Ross, John (1967): Constraints on Variables in Syntax. PhD thesis, MIT, Cambridge, Mass.

Sabel, Joachim (2002): A Minimalist Analysis of Syntactic Islands, The Linguistic Review 19, 271-308.

Sauerland, Uli (1995): Review of 'A-bar Syntax' by Gereon Müller, Glot International 1(8).

Sauerland, Uli (1999): Erasability and Interpretation, Syntax 3, 161-188.

Schäfer, Florian (2007): On the Nature of Anticausative Morphology. PhD thesis, Universität Stuttgart.

Schmellentin, Claudia (2006): PP-Extraktionen. Eine Untersuchung zum Verhältnis von Grammatik und Pragmatik. Niemeyer, Tübingen.

Sportiche, Dominique (1989): Le Mouvement Syntaxique: Contraintes et Paramètres, Langages pp. 35-80.

Stechow, Arnim von (1992): Kompositionsprinzipien und grammatische Struktur. In: P. Suchsland, ed., Biologische und soziale Grundlagen der Sprache. Niemeyer, Tübingen, pp. 175248.

Stechow, Arnim von (2000): Partial Wh-Movement, Scope Marking, and Transparent Logical Form. In: U. Lutz, G. Müller \& A. von Stechow, eds., Wh-Scope Marking. Benjamins, Amsterdam, pp. 447-478.

Stepanov, Artur (2007): The End of CED? Minimalism and Extraction Domains, Syntax 10, 80126.

Sternefeld, Wolfgang (1985): Deutsch ohne grammatische Funktionen: Ein Beitrag zur Rektions- und Bindungstheorie, Linguistische Berichte 99, 394-439.

Sternefeld, Wolfgang (1991): Syntaktische Grenzen. Chomskys Barrierentheorie und ihre Weiterentwicklungen. Westdeutscher Verlag, Opladen.

Sternefeld, Wolfgang (1992): Transformationstypologie und strukturelle Hierarchie. Ms., Universität Tübingen.

Sternefeld, Wolfgang (2006): Syntax. Stauffenburg, Tübingen. Two volumes.

Svenonius, Peter (1994): C-Selection as Feature-Checking, Studia Linguistica 48, 133-155.

Svenonius, Peter (2004): On the Edge. In: D. Adger, C. de Cat \& G. Tsoulas, eds., Peripheries. Syntactic Edges and their Effects. Kluwer, Dordrecht, pp. 261-287.

Szabolcsi, Anna (1994): The Noun Phrase. In: F. Kiefer, ed., Syntax and Semantics, vol 27: The Structure of Hungarian. Academic Press, San Diego, pp. 179-274.

Takahashi, Daiko (1994): Minimality of Movement. PhD thesis, University of Connecticut.

Takano, Yuji (1994): Unbound Traces and Indeterminacy of Derivation. In: M. Nakamura, ed., Current Topics in English and Japanese. Hituzi Syobo, Tokyo, pp. 229-253.

Thiersch, Craig (1985): VP and Scrambling in the German Mittelfeld. Ms., University of Tilburg.

Uriagereka, Juan (1999): Multiple Spell-Out. In: S. Epstein \& N. Hornstein, eds., Working Minimalism. MIT Press, Cambridge, Mass., pp. 251-282.

Webelhuth, Gert (1992): Principles and Parameters of Syntactic Saturation. Oxford University 
Press, Oxford.

Wexler, Ken \& Peter Culicover (1980): Formal Principles of Language Acquisition. MIT Press, Cambridge, Mass.

Williams, Edwin (1974): Rule Ordering in Syntax. PhD thesis, MIT, Cambridge, Mass.

Williams, Edwin (1994): Thematic Structure in Syntax. MIT Press, Cambridge, Mass.

Williams, Edwin (2003): Representation Theory. MIT Press, Cambridge, Mass.

Williams, Edwin (2006): The Subject-Predicate Theory of 'There', Linguistic Inquiry 37, 648651.

Wunderlich, Dieter (1997): Cause and the Structure of Verbs, Linguistic Inquiry 27, 27-68.

Wurmbrand, Susanne (2001): Infinitives. Restructuring and Clause Structure. Mouton de Gruyter, Berlin. 